\title{
Identifying parameters of host cell vulnerability during Salmonella infection by quantitative image analysis and modeling
}

\author{
Jakub Voznica ${ }^{1,2,3}$, Christophe Gardella $^{4,5}$, Ilia Belotserkovsky ${ }^{6}$, Alexandre Dufour ${ }^{2}$, \\ Jost Enninga ${ }^{1}$, Virginie Stévenin ${ }^{1 *}$
}

${ }^{1}$ Institut Pasteur, Dynamics of Host-Pathogen Interactions Unit, 25 rue du Dr. Roux, 75724 Paris, France

${ }^{2}$ Institut Pasteur, Biolmage Analysis Unit, 25 rue du Dr. Roux, 75724 Paris, France

${ }^{3}$ Ecole Normale Supérieure de Cachan, Université Paris-Saclay, 61 avenue du Président Wilson, 94235 Cachan, France

${ }^{4}$ Laboratoire de Physique Statistique, CNRS, UPMC and Ecole Normale Supérieure, 24, rue Lhomond, 75005 Paris, France

${ }^{5}$ Institut de la Vision, INSERM and UPMC, 17 rue Moreau, 75012 Paris, France

${ }^{6}$ Institut Pasteur, Molecular Microbial Pathogenesis Unit, 25 rue du Dr. Roux, 75724 Paris, France

${ }^{*}$ For correspondence:

Virginie Stévenin

virginie.stevenin@ens-cachan.fr

\section{Key words:}

Salmonella enterica serovar Typhimurium, cooperative behavior, cell vulnerability, single-cell heterogeneity, mathematical modeling.

\section{Running title:}

Host cell vulnerability during Salmonella infection 


\begin{abstract}
Salmonella target and enter epithelial cells at permissive entry sites: some cells are more

5 likely to be infected than others. However the parameters that lead to host cell heterogeneity

6 are not known. Here, we quantitatively characterized host cell "vulnerability" towards

7 Salmonella infection based on imaged parameters. We performed successive infections of

8 the same host cell population followed by automated high-throuput microscopy and observed

9 that infected cells have higher probability of being re-infected. Establishing a predictive

10 model we identified two combined origins of host cell vulnerability: the pathogen-induced

11 cellular vulnerability emerging from Salmonella uptake and persisting at later stage of the

12 infection, and the host cell-inherent vulnerability. We linked the host cell inherent vulnerability

13 with its morphological attributes such as the local cell crowding, and with host cell cholesterol

14 content. This showed that the probability of Salmonella infection success can be forecast

15 from morphological or molecular host cell parameters.
\end{abstract}


Salmonella enterica serovar Typhimurium (S. Typhimurium) is a Gram-negative bacterium that causes enteric diseases in many vertebrates after ingestion of contaminated food or water. Salmonellosis is one of the most common causes of food-borne diseases in humans and is considered to be major public health and global economic problem (26). After oral uptake, more than $99 \%$ of $S$. Typhimurium are killed in the stomach or in the gut (2). The surviving bacteria reach the distal ileum where they invade non-phagocytic intestinal epithelial cells (38). In vitro experiments have shown that $S$. Typhimurium invasion of host cells occurs after a phase of bacterial "Near Surface Swimming" (NSS) on the epithelial layer. The bacteria scan the surface and eventually stop and dock at a "selected" host cell $(28,37)$. Docking is irreversible $(29)$ and followed by injection of Salmonella effectors into the host cell through a Type 3 Secretion System (T3SS), leading to the formation of ruffles that engulf the incoming bacterium $(12,22)$. Upon internalization $S$. Typhimurium either develops inside a Salmonella-Containing Vacuole (SCV) or it ruptures the SCV to escape into the cytoplasm where the pathogen replicates at a high rate, a phenomenon called hyperreplication $(H R)(20,33)$.

The mechanism by which $S$. Typhimurium targets specific host cellular sites for its entry remains debated. Santos and colleagues suggested that mitotic cells are selected due to increased cholesterol accumulation at the cell surface during metaphase (32). By contrast, Misselwitz and colleagues proposed that physical obstacles and forces that occur during the process of NSS lead to the targeting of topologically prominent sites, such as dividing cells or membrane ruffles (28). Finally, Lorkowski and colleagues have reported that the invasion of $S$. Typhimurium at the ruffle site is a highly cooperative effort $(25,29)$. Indeed, co-infection of WT and non-invasive $S$. Typhimurium mutants result in the entry of both strains inside the host cells: non-invasive $S$. Typhimurium mutants are trapped at ruffle sites and concomitantly internalized within the host cell, following active invasion by WT S. Typhimurium. However, the cooperative effect between intracellular and entering bacteria remains poorly understood at latter stage of the infection.

An increasing number of studies have highlighted the relevance of intrinsic cellular heterogeneity within eukaryotic monocultures. After seeding, cells display a dynamic range of variability in their morphology depending on their local microenvironment, including local density, and peripheral or central position within cellular islets (35). This heterogeneity results in differences of transcription $(24,9)$, lipid composition $(9,35)$ and sensitivity toward infections (35). Such cell-to-cell variations have been studied during viral infection revealing that simian virus 40 and mouse hepatitis virus present a population-determined pattern of infection associated with differential cell local crowding (35). In the context of bacterial 
1 infection, cell targeting has been related to bacterial cooperation at the entry site and

2 evaluated at the whole population level using Colony Forming Unit (CFU) counting or flow

3 cytometry analysis (25), but so far not in situ at the single cell level.

4

5 Here we investigated the susceptibility of epithelial host cells within the same cell population

6 to become infected by S. Typhimurium. Our analysis revealed that some cells are more likely

7 to be infected by Salmonella than others. We termed them "vulnerable cells". The cell

8 vulnerability was characterized in a quantitative manner by automated high-content imaging

9 through double sequential infections with a delay of 1 to $3 \mathrm{~h}$ between the bacterial

10 challenges. The number of intracellular bacteria per cell as well as the corresponding host

11 cell parameters were assessed, such as cell perimeter, local density, and number of infected

12 neighboring cells. Using a mathematical model, we showed that host cell vulnerability can be

13 induced by a first bacterial uptake but also emerged from its intrinsic morphological and

14 micro-environmental characteristics. 


\section{RESULTS}

\section{Sequential infections allow studies of Salmonella cooperation at the single cell level}

We carried out a microscopy-based double infection assay to explore possible links between host cell vulnerability and successive bacterial infections of epithelial cells (Fig.1). HeLa cells grown in 96-well plates were subjected to a first infection with green $S$. Typhimurium expressing the fluorescent protein GFP $\left(\mathrm{SL}_{G F P}\right)$ for $30 \mathrm{~min}$ followed by elimination of the extracellular bacteria via gentamicin treatment and washing. The cells were then incubated for 1,2 or $3 \mathrm{~h}$ before being subjected to a second wave of infection with red $S$. Typhimurium expressing the fluorescent protein dsRed $\left(\mathrm{SL}_{d s R e d}\right)$. Extracellular bacteria were again eliminated in the same way, and the host cells were stained with CellMask and DAPI before automated image acquisition of entire culture wells (Fig.1A). The obtained images were analyzed with CellProfiler, a widely used image analysis software $(1,17)$ (Fig.1B). The differently labeled bacteria and the stained host cells enabled us to distinguish and quantify distinct cellular populations: those cells infected during the $1^{\text {st }}$ infection $\left(I_{1}\right)$ or not $\left(\right.$ nol $\left.I_{1}\right)$, those infected during the $2^{\text {nd }}$ infection $\left(\mathrm{I}_{2}\right)$ or not $\left(\mathrm{nol}_{2}\right)$, as well as the associated subpopulations $\left(I_{1} \& I_{2}\right.$, nol $_{1} \& \mathrm{nol}_{2}, I_{1} \& \mathrm{nol}_{2}$ and nol $\left._{1} \& I_{2}\right)$ (Fig.1C). We based our analysis on comparing probabilities of infection in these subpopulations.

\section{Cooperation at the entry site during the presence of ruffles}

In order to test the reliability of our method, we analyzed first if we could reproduce previously published results on the ruffle-dependent cooperation between individual salmonellae during host cell entry $(28,25)$. To do this we determined first the time window during which ruffle-associated cooperation could potentially occur performing time-lapse microscopy of Salmonella infection of HeLa cells (Fig. 1D) and Caco-2 cells (data not shown) transiently expressing GFP-tagged actin and labeled with the membrane dye FM 4-64 respectively. Time series of $90 \mathrm{~min}$ at $3 \mathrm{~min}$ intervals provided image sequences with forming and disappearing ruffles. In most of the cases, we observed for both cell lines the uptake of one to two bacteria per ruffle, and we saw ruffle disappearance in less than $15 \mathrm{~min}$ (Video.S1). We noticed that the more bacteria were engulfed by the ruffles, the longer we could detect the presence of these ruffles. Therefore, newly arriving bacteria prompted additional growth of the ruffles (Video.S2). We quantified the ruffle lifetime by measuring the delay of their disappearance after the entry of the last bacterium. The few cases of very high infection ( $>5$ bacteria/ruffle) that could not be properly analyzed were excluded. Quantification revealed an average ruffle lifetime of $13 \mathrm{~min}$ and that $90 \%$ of the ruffles completely disappeared after 24 min (Fig.1D). The results for Caco-2 cell infection were similar to those of HeLa cells. 
2 We then challenged HeLa cells with $S L_{G F P}$ and $S L_{d s R e d}$ at the same time and compared the probability for $S L_{d s R e d}$ to infect the same cell containing simultaneously $S L_{G F P}$ with those that

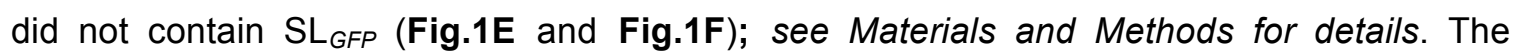
repartition of the different populations of infected cells (Fig.1E) shows a much larger overlap between the cells co-infected with $\mathrm{SL}_{G F P}$ and $\mathrm{SL}_{\text {dsRed }}$ than one would anticipate theoretically for two independent infections. Thus, the efficiency of Salmonella invasion in an individual epithelial cell depends on the concomitant invasion of the same cell by other salmonellae. The difference of the concomitant infection probability (Fig.1F) was striking as it was 8 times more likely for $\mathrm{SL}_{d s R e d}$ to infect a cell also infected by $\mathrm{SL}_{G F P}$ than a cell not infected by $\mathrm{SL}_{G F P}$. Interestingly, increasing the multiplicity of infection (MOI) resulted in a significant increase of the $\mathrm{SL}_{\text {dsRed }}$ infection in cells infected by $\mathrm{SL}_{G F P}$, but not in cells not infected by $\mathrm{SL}_{G F P}$. This result confirmed that the direct effect of an $\mathrm{MOI}$ increase is a higher number of bacteria that infect certain cells rather than an increase of the overall number of cells that become infected. It underlines the relevance of ruffle-associated cooperation between salmonellae at the entry site. Taken together, these results validated that our system was operational.

\section{The probability of being re-infected by Salmonella is higher for already-infected cells, even after the disappearance of the entry ruffles}

To study long-term and ruffle-unrelated cooperative events of Salmonella co-infections, we set the sequential infections with a delay of $1 \mathrm{~h}$ between the two infection waves, killing extracellular bacteria in between through gentamicin treatment. Scanning our time-lapse movies, we were ensured that this time lag led to the complete absence of any remaining entry ruffles from the first infection. In addition, we extended the delay between the two sequential infections to $2 \mathrm{~h}$ and $3 \mathrm{~h}$ (see Fig.1A). We compared the different populations of cells infected during the $2^{\text {nd }}$ infection (population $\mathrm{I}_{2}$ ), depending on whether they were already infected during the first wave of infection (population $I_{2} \mid I_{1}$ ) or not (population $I_{2} \mid$ nol $_{1}$ ) for HeLa (Fig.2A) and Caco-2 (Fig.2B) cells. For both tested cell types, it was significantly more probable for a cell infected the $1^{\text {st }}$ time to be re-infected the $2^{\text {nd }}$ time compared to a cell not previously infected. We propose that such cells are somehow more vulnerable for future infection.

During all sequential infection experiments we also controlled the overall infection efficiencies of $\mathrm{SL}_{G F P}$ and $\mathrm{SL}_{d s R e d}$ at all measured time points ( $1^{\text {st: }} \mathrm{SL}_{G F P}-2^{\text {nd }}: \mathrm{SL}_{d s R e d}$ or in the reverse order) (Fig.S1). In all cases, the percentage of cells infected by each fluorescent Salmonella was similar for cells subjected to single (control) or sequential infections, underlining that sequential infections did not change the overall infection efficiency for the differently colored 
salmonellae. Nevertheless, we noticed a decrease of the amount of infected cells between the early infection and later time points. This effect is most likely due to the technically unavoidable gentamicin treatment between infections. Besides, $\mathrm{SL}_{G F P}$ showed a higher infectivity than $S L_{d s R e d}$ for each condition explained by general deleterious effects of the heterologously overexpressed fluorescent proteins on Salmonella infectivity, and by the partial loss of dsRed expression observed by us and others. Taking into account these issues, we took advantage of the observed consistency of the differences of infection efficiency between the initial and the successive infections, and between $\mathrm{SL}_{G F P}$ and $\mathrm{SL}_{\text {dsRed. }}$. This consistency allows comparative analyses of the ratio of the different infection probabilities, and it provided us with an analytical tool for precise quantification independently of the variances of the differently colored bacteria and technical hurdles of sequential infection.

We defined a "vulnerability score" as the conditional probability for a cell to be infected during the $2^{\text {nd }}$ infection after it had been already infected during the $1^{\text {st }}$ one $\left(I_{2} \mid I_{1}\right)$, divided by the conditional probability for a cell to be infected during the $2^{\text {nd }}$ infection when it had not been previously infected $\left(I_{2} \mid\right.$ nol $\left._{1}\right)$ (described in more detail in Materials and Methods). We also analyzed changes of the vulnerability score in time comparing cells subjected to sequential infection with 1, 2 and $3 \mathrm{~h}$ delays (Fig.2B and Fig.S2 for detailed representation of the conditional probability for each replicate). Surprisingly, the vulnerability score appeared unaltered. We obtained similar results inverting the order of the used pathogen, infecting first with $\mathrm{SL}_{d s R e d}$ and then with $\mathrm{SL}_{G F P}$ (Fig.S3). It was not possible to shorten the delay between infections to less than $1 \mathrm{~h}$ due to the ruffle influence, and we could not extend it beyond $3 \mathrm{~h}$ due to potential release of hyper-replicative (HR) bacteria from the first infection into the extracellular medium that could then re-infect new cells during the $2^{\text {nd }}$ wave of infection. Altogether, these results showed that, after ruffle disappearance, the infected cells remain more vulnerable to a new infection than the non-infected ones, and this vulnerability is stable in time.

\section{Cell vulnerability to secondary infection can be predicted from the number of intracellular bacteria}

So far, we only considered the character "infected" or "non-infected" for each cell after SLGFP and $\mathrm{SL}_{\text {dsRed }}$ infections that provides global trends on their interaction. To further exploit our data we quantified the number of bacteria per host cell and related the obtained numbers with the previously extracted vulnerability scores. The distribution of intracellular bacteria inside infected cells at $2.5 \mathrm{~h}$ post-infection (pi) showed that most of the cells contained few 
bacteria, and the proportion of cells with higher number of intracellular bacteria decreases drastically. Overall, we were able to distinguish three groups of infected cells: the ones containing one to two intracellular bacteria (35\% of the global population), the ones containing three to eight intracellular bacteria (39\% of the global population) and the ones containing more than nine intracellular bacteria ( $26 \%$ of the global population), corresponding respectively to low, medium and high infections (Fig.3A).

We compared the vulnerability score of these three infection groups during sequential double infections (Fig.3B). This analysis revealed that the more bacteria had entered in a given host cell during the first infection, the more it was likely that this cell became re-infected. Such tendencies still emerged when the bacteria were not grouped, but analyzed individually, underlining the robustness of this result (Fig.S4).

Then, we investigated how the level of bacterial uptake during the second infection depends on the number of intracellular bacteria of the first infection. For this we quantified the probability for a cell to be highly infected during the second infection as a function of the efficiency of the first uptake (Fig.3C). We found that the more intracellular bacteria had been internalized during the first infection, the more likely they were to ingest a high amount of new bacteria during the second infection. Therefore, we propose that cell vulnerability is maintained from the first to the second infection.

\section{Cell vulnerability as intrinsic or induced property}

The results from the sequential infections (Fig.3 and Fig.4) provided quantitative scores of cell vulnerability towards Salmonella infection. We secondly investigated the origin of the observed cell vulnerability. Two possibilities can be anticipated: (i) the cellular vulnerability would be an intrinsic host cell attribute (hypothesis 1: "intrinsic vulnerability") or (ii) it would be induced by bacterial uptake (hypothesis 2: "induced vulnerability") (Fig.4A). In theory, these hypotheses can be distinguish by the observable different probability of the $2^{\text {nd }}$ wave of infection occurring in previously non-infected cells $\mathrm{P}\left(\mathrm{I}_{2} \mid\right.$ nol $\left._{1}\right)$ as depicted in the two schemes of Fig.4B and described as follows: In the case of vulnerability as intrinsic attribute, the probability of infection $\mathrm{P}\left(\mathrm{I}_{2} \mid\right.$ nol $\left._{1}\right)$ would be lower than $\mathrm{P}\left(\mathrm{I}_{2 \mathrm{Ctr}}\right)$ as the pool of vulnerable cells would be already partially consumed during the $1^{\text {st }}$ sequential infection, whereas it would remain conserved in the control (Fig.4B-left). In the case of induced vulnerability, the probability of infection $\mathrm{P}\left(\mathrm{I}_{2} \mid\right.$ nol $\left._{1}\right)$ would be similar to $\mathrm{P}\left(\mathrm{I}_{2 \mathrm{Ctr}}\right)$, as the cells would be considered with equivalent vulnerabilities before their first infection (Fig.4B-right). The experimental data obtained did not show a significant difference between $P\left(I_{2} \mid\right.$ nol $\left.I_{1}\right)$ and $P\left(I_{2 C t r}\right)$ (t-test $p$ value $>0,05$ ) (Fig.4C), suggesting that vulnerability may be induced by bacterial uptake 
(Fig.4B, hypothesis 2). Taking into account the small percentage of cells belonging to the studied subpopulations we caution that the absence of a statistically significant difference between these populations did not allow to exclude the first hypothesis of host cell inherent vulnerability.

\section{Single cell vulnerability to Salmonella infection is a combination of intrinsic and induced vulnerability}

Considering that the subpopulation comparison could not exclude an involvement of inherent vulnerability, we developed a mathematical model to evaluate the relative contribution of induced and inherent vulnerability to the overall cell vulnerability towards Salmonella infection. To investigate the contribution of cell parameters at the single-cell level, we measured different intrinsic variables that could influence cellular vulnerability, namely the cell morphology (cell perimeters, cell circularity), the local environment (local cell density, number of infected and non-infected neighboring cells), and the above-analyzed features of the Salmonella infection (delay between infections, load of intracellular bacteria per cell from $I_{1}$ ) (Fig.5A). We extracted all these elements using Icy, an image analysis software (6) recently used for Salmonella infection studies in situ (27) (see Fig.S5A for illustration of Icy cell segmentation).

First, we analyzed the distribution of distinct cellular parameters in either infected or in noninfected HeLa (upper panels) and Caco-2 (lower panels) cell populations (Fig.5A). For both cell types, the infected cells displayed distinct cellular features in comparison to the noninfected cells, such as a higher local crowding reflected by a higher number of neighboring cells in direct contact. Comparing the relative correlations of the cellular parameters, we highlight the presence of strong links between a number of them (Fig.S5B-C, S6 and S7). In particular cell morphology is highly dependent on the local micro-environment, such as the local cell density that negatively correlates with the cell perimeter in HeLa and Caco-2 cells. Interestingly, cells infected during the second bacterial challenge are more likely to be nearby cells infected during the first bacterial challenge ("infected neighbor cells") than by noninfected neighbor cells. Thus Salmonella infection of one cell increases the probability of its neighboring cells to be subsequently infected.

To quantify the direct involvement of each studied parameter on the overall cell vulnerability we developed a statistic modeling approach adapted to our high-throughput microscopy dataset on sequential Salmonella infection. This model is based on a logistic regression able to predict the infection efficiency at the single cell level from cellular parameters. We 
measured the contribution of each parameter for the prediction by estimating how well the model predicts compared to a model that would ignore one parameter; as described in Materials and Methods (Fig.5B). Taken separately, the load of intracellular bacteria resulting from $I_{1}$ directly improved the prediction of cell vulnerability towards subsequent infection (Fig.5B). Thus, host cell vulnerability is induced by bacterial uptake, which is in line with our experimental data. In addition, the host cell parameters linked with cell morphology and local environment also significantly improved the model prediction of infection for HeLa and for Caco-2 cells (see Table1 and Table2 for model details and the value of the coefficients). Together, our modeling approach revealed that single host cell vulnerability to Salmonella infection is a combination of intrinsic and bacterial-induced vulnerability.

We quantified their relative involvement by calculating the model-based fold change of the probability of infection for a cell not infected and having a low score of inherent vulnerability with a cell infected and/or having a high score of inherent vulnerability (Fig.5C). This showed that induced and intrinsic vulnerability have both a strong impact on the overall cell vulnerability. Interestingly, the induced vulnerability is more prevalent for Salmonella infection of HeLa cells (2,2 fold-increase) than infection of Caco-2 cells (1,3 fold-increase), whereas the inherent vulnerability plays a more prominent role for Caco- 2 cell infections $(2,6$ foldincrease) than for HeLa cells (1,6 fold-increase). From these findings we conclude that the analyzed host cell parameters are differentially involved in relation to cell vulnerability towards Salmonella infection depending of the cell type. In particular, the local cell density increases the cell vulnerability for HeLa cells but decreases it for Caco-2 cells (Fig.5D). This could be explained by the polarization of the Caco-2 at high confluency and highlights the specificity of each predicted model for a given cell-type.

We also investigated whether the first infection affects the inherent host cell parameters, we compared the correlation between parameters that were identified as being either involved or not involved in the inherent vulnerability of the cell. As their correlations were similar in infected and non-infected cells (data not shown) we concluded that Salmonella infection did not impact the implication of the studied inherent cell parameters.

\section{Reliability of the model-based prediction of infection}

To investigate the spatial distribution of the cell vulnerability among the cell population, we created "vulnerability maps" from original images of the cell population after labeling each cell nucleus with a color corresponding to its probability of infection (Fig.6A). Notably, we could confirm that on average the infected cells were properly assigned with a higher prediction score to be infected than the non-infected ones (see Fig.S8 for quantification). Based on our vulnerability maps, the predicted infected cells showed a very good overlap or 
were in close vicinity with the experimentally infected cells (Fig.6A). This illustrates the reliability of our approach in a qualitative way, and it also underlines the impact of local micro-environment on cell vulnerability. We went on and quantified the veracity of the HeLa and Caco-2 adapted models when confronted with 100 experimentally measured infected and 100 experimentally measured non-infected cells. For both cell-types, models allowed a good prediction in the majority of the cases, $62 \%$ for HeLa and $66 \%$ for Caco-2 respectively (Fig.6B). Taken together, these results attest that the probability of Salmonella infection success can be forecast at the near single-cell level based on host cell parameters.

\section{Involvement of cellular cholesterol rate as an inherent vulnerability factor}

To investigate molecular players that are linked with the inherent cell vulnerability to Salmonella infection, we analyzed the plasma membrane composition as main feature known to be relevant for Salmonella infection. We focused on cholesterol as cells at low crowding present a higher amount of free cholesterol than cells at high crowding (9). We monitored the relation between global cellular cholesterol levels and host cell targeting performing Salmonella infection of HeLa cells for 30 min followed by cholesterol labeling via filipin staining and flow cytometry analysis (Fig.7). For each experiment, we binned the total cell population into five subpopulations corresponding to increasing cellular levels of cholesterol that we classified as 1 to 5 , with each subpopulation containing $20 \%$ of the total cells (see Fig.S9 for FACS gating details). Comparing the number of infected cells in these different subpopulations with different amounts of cholesterol, we revealed that the probability of infection decreased with increasing cholesterol levels. From this we conclude that cells with a lower amount of cholesterol are preferentially targeted by Salmonella compared to those with higher cholesterol levels. 


\section{DISCUSSION}

Cellular heterogeneity describes cases in which genetically identical cells present different behaviors and morphologies. This biological phenomenon is commonly present in an epithelial layer of an individual as well as within a monolayer of cultured cells. Despite the realization of the importance of cellular heterogeneity, its study has only become feasible during recent years, mainly thanks to the implementation of novel technologies such as imaging and computer-assisted analysis. In the context of pathogen infection, this heterogeneity produces cells unequally vulnerable or resistant which impacts on the overall infection.

We investigated the cell vulnerability of epithelial cells for $S$. Typhimurium infection. According to our results, infected cells display a strikingly higher probability of being reinfected with Salmonella, even after disappearance of membrane ruffles. We obtained similar results in two relevant epithelial cell lines, HeLa and Caco-2, suggesting that this represents a conserved propensity towards Salmonella infection. The measured cellular vulnerability remained unaltered for all measured time-points ranging from a delay of $1 \mathrm{~h}$ to $3 \mathrm{~h}$ between the infections. Attributing a "vulnerability score" to the challenged cells, we showed a higher vulnerability score in cells previously infected, and we found that this score increases with the amount of intracellular bacteria contained by a given cell. This result raises the issue of the bacterial impact on the cell vulnerability. Therefore, we aimed at distinguishing inherent cell vulnerability from the one induced by bacterial uptake (Fig.4A, hypothesis 1 and 2 respectively) exploiting the imaging data obtained via a high-content analytical pipeline. This allowed visualization of the infection in situ and provided a large number of associated cellular parameters. We quantified the implication of specific parameters associated with individual cells on the cell vulnerability towards Salmonella infection. It appeared clearly that the efficiency of early bacterial uptake during the first infection directly determines cell vulnerability. Thus Salmonella induce an increase of the cell vulnerability toward subsequent infections.

While long-term cooperation between bacteria has been intensively studied for communities of bacteria living in a common extracellular environment (5), little is known about the cooperation between intracellular and extracellular bacteria leading to increased bacterial uptake. Nevertheless, this phenomenon has been investigated more extensively for many viruses, including bacteriophages (4), influenza virus (14), poxviruses (7, 21), flaviviruses (39, 34), alphaviruses (18), and alphaherpesviruses (3). Generally, those works have demonstrated that the first virus to infect a cell has the capacity to prevent co-infection of other viruses belonging either to the same strain, or to more distantly related or unrelated 
strains. It is termed "superinfection exclusion" and may protect limited cellular resources and promote the replication and dissemination of the originally infecting virus. By analogy, the increased probability of cellular re-infection by Salmonella can be phrased as a "superinfection promotion". It remains to be clarified if such process is relevant for all intracellular bacteria. For instance and in contrast to Salmonella infection, Jorgensen et al reported that the Chlamydia effector protein CPAF secreted from bacteria within mature inclusions prevents those that are still extracellular to invade (16). Thus, CPAF could be a factor mediating Chlamydia resistance towards superinfection.

Our approach also allowed the relative quantification of the impact of different host cell parameters on the inherent vulnerability of host cell to Salmonella infection. In particular, morphological attributes and local cell crowding are highly linked with this vulnerability. Cell crowding as major determinant for the probability to become infected has been proposed by Snijder and colleagues in the context of viral infection. They showed that during infections by the simian virus SV40 or the mouse hepatitis virus (MHV), the targeted cells have different localization within cell islets (35). SV40 and MHV infect preferentially either peripheral or central cells, a phenomenon that is linked with the differential expression levels of focal adhesion kinase and the presence of sphingolipid GM1 at the plasma membrane of challenged host cells. Thus, similarly to several viral infections, the probability of infection of a single cell by Salmonella is influenced by its local environment.

Our analytical tools will be useful for further studies on Salmonella, and for other researchers working on different intracellular bacteria pathogens, such as Chlamydia, Listeria or Shigella (see Materials and Methods). We revealed that some cells are indeed intrinsically more vulnerable to Salmonella and will be targeted by the bacteria first. Most of the tested parameters appeared relevant for model-based infection prediction but are differentially involved in the cell vulnerability depending on the cell-type studied. Developing an adapted model based on host cell parameters we could forecast the probability of Salmonella infection success at the near single-cell level. Interestingly, the number of infected neighboring cells is highly increased in the population of infected cells. Cases of bacterial uptake impacting on the cells neighboring the infection (called bystander cells) have been previously reported for Shigella that induces an IL-8 immune response after NFKB activation detectable from $2 \mathrm{~h}$ pi in $70 \%$ of the bystander cells (19). However, it is not known whether the neighboring cells are also more sensitive towards Shigella entry.

Because of our incomplete knowledge of host factors that are involved in the early attachment, such as potential entry receptors, it remains difficult to identify the molecular 
mechanisms that establish the differential vulnerability during Salmonella infection. Although receptors for direct recognition of Salmonella have been proposed, such as the cystic fibrosis transmembrane conductance regulator (CFTR) (31) and the epithelium growth factor receptor (EGFR) (30), many cell types infected by Salmonella do not express them (15). Therefore, it has been proposed that recognition mechanisms likely involve more ubiquitous factors (10). To explore molecular cues involved in the inherent heterogeneity of host cell vulnerability, we decided to investigate the membrane lipid composition, in particular cellular cholesterol. This was based on previous studies showing that the amount of free cholesterol per cell negatively correlates with the local cell crowding (9). We found that an increase of cholesterol amount at single cell level correlates with a lower vulnerability of the cell, so that Salmonella preferential target host cells with low amounts of cholesterol. Intriguingly, these results on an implicated host molecule are in agreement with the morphological feature of local density; HeLa cells at high density contain lower amounts of cholesterol and display an increased inherent cell vulnerability. The role of cholesterol during Salmonella infection is still debated. Several studies have demonstrated that the Salmonella SipB effector and translocon component requires cholesterol for proper functioning $(13,10)$. In this context, it should be noted that the translocons operate in small cholesterol-rich microdomains at the plasma membrane and cannot be linked readily with the overall cholesterol levels. Furthermore, those studies were based on sterol sequestering agents and biosynthesis inhibitors. Contrastingly, Gilk and colleagues showed that cholesterol is not essential for Salmonella invasion and intracellular replication inside host cells using an original mouse model, (11). In our study we highlighted that non-treated cells with a low amount of global cellular cholesterol are preferentially targeted by Salmonella, which does not exclude a potential involvement of cholesterol at the subcellular level.

In conclusion, our study represents a first step in understanding Salmonella cell targeting and provides a path for the identification of cellular and bacterial factors involved in host cell vulnerability. Such factors could be targeted to render a cell more resistant to pathogen infections, allowing potential new therapeutic strategies. Together, our study delineates in a quantitative manner the importance of vulnerable cell recognition and bacterial cooperation for cell targeting by $S$. Typhimurium. 


\section{MATERIALS AND METHODS}

\section{Bacterial Strains}

The following S. Typhimurium were used: SL1344 (wild type), SL1344 pM965 (SalmonellaGFP) described by Stecher et al (36), and SL1344 pGG2 (Salmonella-dsRed) obtained after transformation of SL1344 with the pGG2 plasmid described by Lelouard et al (23). Bacteria were grown in Lysogeny Broth (LB) medium supplemented with $0.3 \mathrm{M} \mathrm{NaCl}$ and ampicillin at $50 \mu \mathrm{g} / \mathrm{ml}$ at $37^{\circ} \mathrm{C}$ in an orbital shaker.

\section{Cell Culture}

All cell culture reagents were purchased from Invitrogen unless otherwise stated. Human epithelial HeLa cells (clone CCL-2 from ATCC) were cultured in Dulbecco's Modified Eagle's Medium (DMEM) supplemented with $10 \%(\mathrm{v} / \mathrm{v})$ fetal bovine serum (FBS), at $37^{\circ} \mathrm{C}, 5 \% \mathrm{CO}_{2}$. Intestinal epithelial Caco-2 TC7 cells (kindly provided by P. Sansonsetti) were grown in DMEM supplemented with $10 \% \mathrm{FBS}$ at $37^{\circ} \mathrm{C}, 10 \% \mathrm{CO}_{2}$. All infection assays were performed in EM buffer $\left(120 \mathrm{mM} \mathrm{NaCl}, 7 \mathrm{mM} \mathrm{KCl}, 1.8 \mathrm{mM} \mathrm{CaCl}_{2}, 0.8 \mathrm{mM} \mathrm{MgCl}_{2}, 5 \mathrm{mM}\right.$ glucose, $25 \mathrm{mM}$ HEPES, pH 7.4). HeLa cells were transfected with pEGFP-actin plasmid DNA (8) from a maxiprep, using the X-tremeGENE 9 DNA transfection reagent (Roche) for $48 \mathrm{~h}$.

\section{Double Infection Assays}

For invasion experiments, overnight bacterial cultures were sub-cultured 1/20 and grown until late exponential/early stationary phase. Before infection, bacteria were gently washed and resuspended in EM buffer. Bacteria were added to the cells at an $\mathrm{MOI}$ of 30 corresponding to CFU, and incubated for $30 \mathrm{~min}$ at $37^{\circ} \mathrm{C}, 5 \% \mathrm{CO}_{2}$. Non-internalized bacteria were eliminated by washing 3 times with warm EM buffer and incubated for 1,2 or $3 \mathrm{~h}$ at $37{ }^{\circ} \mathrm{C}, 5 \% \mathrm{CO}_{2}$. Adding EM buffer containing $100 \mu \mathrm{g} / \mathrm{ml}$ gentamicin for $1 \mathrm{~h}$ killed extracellular bacteria. The concentration of gentamicin was then decreased to $10 \mu \mathrm{g} / \mathrm{ml}$ and $10 \%$ FBS was added to the medium. At the desired time points, the cells were washed again in EM buffer to eliminate the remaining gentamicin and re-infected with a fresh batch of sub-cultured bacteria following the same protocol. After killing the extracellular bacteria again by a $1 \mathrm{~h}$ of incubation with EM buffer containing $100 \mu \mathrm{g} / \mathrm{ml}$ gentamicin, the cells were fixed with $4 \%$ paraformaldehyde at room temperature for immunofluorescence analysis.

\section{Microscopy}

All image acquisitions were performed on a Nikon inverted widefield microscope using a 20x/0.5NA air objective, an automatic programmable XY-stage and the Nikon perfect focus system. For sequential infections, 161 fields were imaged per well and four channels per field 
were captured using a CoolSnap2 camera (Roeper Scientific). Nuclei and cells were stained using DAPI (excitation/emission wavelengths: $350 / 470 \mathrm{~nm}$ ) and the cell bodies with CellMask DeepRed Plasma Membrane Stain (ThermoFisherScientific, excitation/emission wavelengths: $640 / 670 \mathrm{~nm}$ ) respectively. Caco-2 cells were stained with the $F M \circledast 4-64$ membrane dye (Invitrogen) before time lapse imaging (excitation/emission wavelengths: $558 / 734 \mathrm{~nm}$ ). Quantification of the ruffle timing was performed on the same microscope, using a 20x/0.5NA air objective and time intervals of $3 \mathrm{~min}$ for $90 \mathrm{~min}$. Time lapse imaging of ruffles was performed on a DeltaVision widefield microscope using a 60x/1.42 NA oil objective and z-stacks with a spacing of $500 \mathrm{~nm}$. The images were subsequently deconvolved using DeltaVision Elite integrated software.

\section{Cholesterol measurements}

HeLa cells were challenged with $S L_{G F P}$ for 30 min before trypsinization, fixation with $4 \%$ paraformaldehyde and incubation with $16 \mathrm{ug} / \mathrm{mL}$ filipin complex from Streptomyces filipinensis (Sigma-Aldrich). This treatment was directly followed by FACS measurement on BD FACS CANTO cytometer using the excitation/emission wavelengths of 405/450 nm and 488/530 $\mathrm{nm}$ for filipin and GFP fluorescence detection respectively. Infected and non-infected cells were distinguished using the green fluorescence emitted by $\mathrm{SL}_{G F P}$ (see Fig.S9 for gating details). Data were processed using FlowJo software.

\section{Image Analysis}

All images were analyzed with two open source software: CellProfiler (http://cellprofiler.org/) and Icy (http://icy.bioimageanalysis.org/). CellProfiler was used to detect each single cell and the number of its intracellular salmonellae expressing either GFP or dsRed. The following modules were used during the analysis: IdentifyPrimaryObjects recognized nuclei and bacteria; IdentifySecondaryObjects identified cells (here the secondary objects) by extending the nuclear area previously recognized; RelateObjects assigned bacteria within individual cells. Icy was used for accurate detection of cell borders and the cellular microenvironment analysis. We used a graphical environment called Protocols for the development of an analytical pipeline including the following plugins: HK-Means that identify nuclei by pre-filtering the signal to identify objects within a size range; Spot Detector that identify bacteria; Active Contours that identify the edges of the plasma membrane by propagating the Region of Interest (ROI) detected for the nuclei; and Javascript that parent the ROI of cells with bacteria, to measure local cell density and to distinguish which neighboring cells are infected by which bacteria. 


\section{Probability}

$P\left(I_{2} \mid I_{1}\right)$ means "Probability of the $2^{\text {nd }}$ sequential infection, knowing that the cell has been infected by the $1^{\text {st }}$ one" and is calculated as follows:

$$
P\left(I_{2} \mid I_{1}\right)=P\left(I_{1} \& I_{2}\right) / P\left(I_{1}\right)
$$

Where $P\left(I_{1}\right)=$ [Number of cells in $I_{1} /$ Total number of cells], and $P\left(I_{1} \& I_{2}\right)=$ [Number of cells in $I_{1} \& I_{2} /$ Total number of cells].

$\mathrm{P}\left(\mathrm{I}_{2} \mid \mathrm{no}_{1}\right)$ means "Probability of the $2^{\text {nd }}$ sequential infection, knowing that the cell has not been infected by the $1^{\text {st }}$ one" and is calculated as follows:

$$
P\left(I_{2} \mid \text { noI }_{1}\right)=P\left(I_{2} \& \text { noI }_{1}\right) / P\left(\text { noI }_{1}\right)
$$

Where $P\left(\right.$ nol $\left._{1}\right)=\left[\right.$ Number of cells in nol ${ }_{1} /$ Total number of cells $]$, and $P\left(I_{2} \&\right.$ nol $\left.I_{1}\right)=[$ Number of cells in nol $_{1} \& l_{2} /$ Total number of cells].

\section{Model}

We modeled the influence of multiple parameters on the probability of a second infection. A Boolean variable $Y$ represents the second infection: It is equal to 1 for infected cells and 0 otherwise. Its probability is predicted by the following seven parameters: Load of infection (LOI) represents the number of infecting bacterium during the first infection, separated in 4 groups corresponding to no (0 bacteria), low (1 or 2 ), medium (3 to 8 ) or high $(9+)$ infection. Delay is a categorical variable corresponding to the delay between the $1^{\text {st }}$ and the $2^{\text {nd }}$ infections (1, 2 or $3 \mathrm{~h}$ ). Infected neighbor cells (X1) refers to the number of cells in contact that had been infected during the first infection. Non-Infected neighbor cells (X2) refers to the number of cells in contact which had not been infected during the first infection. Local Cell Density (X3) is the number of cells present in a vicinity of $100 \mu \mathrm{m}$. The distance is calculated between the center of the nuclei. Cell perimeter (X4) is the length of the perimeter of the cell (in $\mu \mathrm{m}$ ) obtained after segmentation. Circularity (X5) refers to the cell

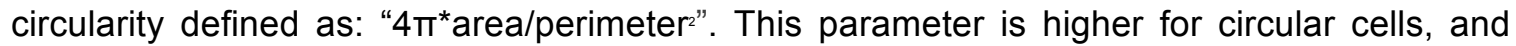
lower for cells that are elongated or have complex shape, but does not depend a priori on the cell size. In practice we used to its square root. The probability of $Y$ during the second infection is modeled as:

$$
P(Y=1 \mid X 1, \ldots, X n)=1 /[1+\exp (-(a L O I+\text { aDelay }+a 1 X 1+\ldots+a 5 X 5))]
$$

where aLOI (resp. aDelay) has a different value for each of the LOI categories (resp. Delay categories), and $\mathrm{a}_{1}, \ldots, \mathrm{a}_{5}$ are constants. All parameters were learned by maximizing the likelihood of the model, e.g. the probability of the observed data as measured by the model. We used 115000 and 327000 cells to train and test the model for HeLa and Caco-2 cells respectively. We divided the cell population into two random sets; the training set $\left(9 / 10^{\text {th }}\right.$ of the cells per replicate) and testing set $\left(1 / 10^{\text {th }}\right.$ of the cells) and computed the likelihood of infection observed in the testing set. The higher the likelihood, the better the 
parameters of the model predicted infection. We repeated this procedure 100 times. To measure the improvement of infection prediction by taking into account each parameter, the likelihood of the complete model was compared (on a log scale) with the likelihood of seven models ignoring each time one parameter. This difference of log-likelihood is reported in Fig.5B.

Quantification of the impact of a parameter towards cell vulnerability was obtained by applying our statistical model to the $1^{\text {st }}$ and the $3^{\text {rd }}$ quantile values of a given parameter, while other parameters were kept equal at their median values. We obtained the probabilities of the second infection for these two sets and reported their ratio. In Fig.5D, the arrows " $\boldsymbol{\lambda}$ " and "צ" correspond to a ratio above and under 1 respectively. The parameters-values corresponding to a low inherent vulnerability of HeLa and Caco-2 cells were the following: local cell density $\left(1^{\text {st }}\right.$ quantile and $3^{\text {rd }}$ quantile respectively), cell perimeter ( $1^{\text {st }}$ quantile), infected neighboring cells (median), non-infected neighboring cells (median), circularity (median and $3^{\text {rd }}$ quantile respectively). The parameters-values corresponding to a high inherent vulnerability of HeLa and Caco-2 cells were the following: local cell density $\left(3^{\text {rd }}\right.$ quantile and $1^{\text {st }}$ quantile respectively), cell perimeter ( $3^{\text {rd }}$ quantile), infected neighboring cells (median), non-infected neighboring cells (median), circularity (median and $1^{\text {st }}$ quantile respectively).

Models reliability was evaluated using 100 infected and 100 non-infected cells and quantifying the amount of "good predictions" among those cells. We repeated this procedure 100 times and showed the average. As a comparison, a random model would provide approximately $50 \%$ of "good predictions".

\section{Statistical analysis}

The statistical analysis was performed using $\mathrm{R}$ and GraphPad Prism. T-tests were used to evaluate the significance of the results, referred like ${ }^{*},{ }^{* *},{ }^{* * *}$ for $p$-values $<0.05,<0.01$, and $<0.001$, respectively.

\section{Data availability}

The pipeline used on CellProfiler and on ICY, as well as the R code used to generate the model can be provided by the authors. 


\section{REFERENCE}

1. Carpenter, A. E. et al. CellProfiler: image analysis software for identifying and quantifying cell phenotypes. Genome Biol. 7, R100 (2006).

2. Carter, P. B. \& Collins, F. M. The route of enteric infection in normal mice. J. Exp. Med. 139, 1189-203 (1974).

3. Criddle, A., Thornburg, T., Kochetkova, I., DePartee, M. \& Taylor, M. P. gDIndependent Superinfection Exclusion of Alphaherpesviruses. J. Virol. 90, 4049-4058 (2016).

4. Cumby, N., Davidson, A. R. \& Maxwell, K. L. The moron comes of age. Bacteriophage 2, 225-228 (2012).

5. Davey, M. E. \& O'toole, G. A. Microbial biofilms: from ecology to molecular genetics. Microbiol. Mol. Biol. Rev. 64, 847-67 (2000).

6. de Chaumont, F. et al. Icy: an open bioimage informatics platform for extended reproducible research. Nat. Methods 9, 690-696 (2012).

7. Doceul, V., Hollinshead, M., van der Linden, L. \& Smith, G. L. Repulsion of superinfecting virions: a mechanism for rapid virus spread. Science 327, 873-876 (2010).

8. Ehsani, S. et al. Hierarchies of host factor dynamics at the entry site of Shigella flexneri during host cell invasion. Infect. Immun. 80, 2548-2557 (2012).

9. Frechin, M. et al. Cell-intrinsic adaptation of lipid composition to local crowding drives social behaviour. Nature 523, 88-91 (2015).

10. Garner, M. J., Hayward, R. D. \& Koronakis, V. The Salmonella pathogenicity island 1 secretion system directs cellular cholesterol redistribution during mammalian cell entry and intracellular trafficking. Cell. Microbiol. 4, 153-165 (2002).

11. Gilk, S. D. et al. Bacterial Colonization of Host Cells in the Absence of Cholesterol. PLoS Pathog. 9, (2013).

12. Haraga, A., Ohlson, M. B. \& Miller, S. I. Salmonellae interplay with host cells. Nat. Rev. Microbiol. 6, 53-66 (2008).

13. Hayward, R. D. et al. Cholesterol binding by the bacterial type III translocon is essential for virulence effector delivery into mammalian cells. Mol. Microbiol. 56, 590603 (2005).

14. Huang, I. C. et al. Influenza A virus neuraminidase limits viral superinfection. J Viro/ 82, 4834-4843 (2008).

15. Jones, B. D., Paterson, H. F., Hall, a \& Falkow, S. Salmonella typhimurium induces membrane ruffling by a growth factor-receptor-independent mechanism. Proc. Natl. Acad. Sci. U. S. A. 90, 10390-10394 (1993). 
16. Jorgensen, I. et al. The chlamydia protease CPAF regulates host and bacterial proteins to maintain pathogen vacuole integrity and promote virulence. Cell Host Microbe 10, 21-32 (2011).

17. Kamentsky, L. et al. Improved structure, function and compatibility for cellprofiler: Modular high-throughput image analysis software. Bioinformatics 27, 1179-1180 (2011).

18. Karpf, a R., Lenches, E., Strauss, E. G., Strauss, J. H. \& Brown, D. T. Superinfection exclusion of alphaviruses in three mosquito cell lines persistently infected with Sindbis virus. J. Virol. 71, 7119-7123 (1997).

19. Kasper, C. A. et al. Cell-cell propagation of NF-??B transcription factor and MAP kinase activation amplifies innate immunity against bacterial infection. Immunity 33, 804-816 (2010).

20. Knodler, L. A. Salmonella enterica: Living a double life in epithelial cells. Curr. Opin. Microbiol. 23, 23-31 (2015).

21. Laliberte, J. P. \& Moss, B. A novel mode of poxvirus superinfection exclusion that prevents fusion of the lipid bilayers of viral and cellular membranes. J. Virol. 88, 975168 (2014).

22. LaRock, D. L., Chaudhary, A. \& Miller, S. I. Salmonellae interactions with host processes. Nat. Rev. Microbiol. 13, 191-205 (2015).

23. Lelouard, H. et al. Pathogenic Bacteria and Dead Cells Are Internalized by a Unique Subset of Peyer's Patch Dendritic Cells That Express Lysozyme. Gastroenterology 138, 173-184.e3 (2010).

24. Liberali, P., Snijder, B. \& Pelkmans, L. Single-cell and multivariate approaches in genetic perturbation screens. Nat. Rev. Genet. 16, 18-32 (2014).

25. Lorkowski, M., Felipe-López, A., Danzer, C. A., Hansmeier, N. \& Hensel, M. Salmonella enterica invasion of polarized epithelial cells is a highly cooperative effort. Infect. Immun. 82, 2657-2667 (2014).

26. Majowicz, S. E. et al. The Global Burden of Nontyphoidal Salmonella Gastroenteritis. Clin. Infect. Dis. 50, 882-889 (2010).

27. McQuate, S. E. et al. Long-term live-cell imaging reveals new roles for Salmonella effector proteins SseG and SteA. Cell. Microbiol. (2016). doi:10.1111/cmi.12641

28. Misselwitz, B. et al. Near surface swimming of salmonella Typhimurium explains target-site selection and cooperative invasion. PLoS Pathog. 8, 9 (2012).

29. Misselwitz, B. et al. Salmonella enterica serovar typhimurium binds to hela cells via fim-mediated reversible adhesion and irreversible type three secretion system 1mediated docking. Infect. Immun. 79, 330-341 (2011).

30. Pace, J., Hayman, M. J. \& Galán, J. E. Signal transduction and invasion of epithelial cells by S. typhimurium. Cell 72, 505-514 (1993). 
2

31. Pier, G. B. et al. Salmonella typhi uses CFTR to enter intestinal epithelial cells. Nature 393, 79-82 (1998).

32. Santos, A. J. M., Meinecke, M., Fessler, M. B., Holden, D. W. \& Boucrot, E. Preferential invasion of mitotic cells by Salmonella reveals that cell surface cholesterol is maximal during metaphase. J. Cell Sci. 126, 2990-2996 (2013).

33. Santos, J. C. \& Enninga, J. At the crossroads: Communication of bacteria-containing vacuoles with host organelles. Cell. Microbiol. 18, 330-339 (2016).

34. Schaller, T. et al. Analysis of hepatitis $C$ virus superinfection exclusion by using novel fluorochrome gene-tagged viral genomes. J. Virol. 81, 4591-603 (2007).

35. Snijder, B. et al. Population context determines cell-to-cell variability in endocytosis and virus infection. Nature 461, 520-523 (2009).

36. Stecher, B. et al. Flagella and Chemotaxis Are Required for Efficient Induction of Salmonella enterica Serovar Typhimurium Colitis in Streptomycin-Pretreated Mice Flagella and Chemotaxis Are Required for Efficient Induction of Salmonella enterica Serovar Typhimurium Colitis. Infect Immun 72, 4138-4150 (2004).

37. Vonaesch, P. et al. Quantitative insights into actin rearrangements and bacterial target site selection from SalmonellaTyphimurium infection of micropatterned cells. Cell. Microbiol. 15, 1851-1865 (2013).

38. Watson, K. G. \& Holden, D. W. Dynamics of growth and dissemination of Salmonella in vivo. Cell. Microbiol. 12, 1389-1397 (2010).

39. Zou, G. et al. Exclusion of West Nile virus superinfection through RNA replication. J. Virol. 83, 11765-11776 (2009). 


\section{Acknowledgments}

2 We thank Jennifer Fredlund and Andrew Rutenberg for their help during the initial phase of

3 the project, Adrien Sauvaget, Claude Loverdo, Kristine Schauer and Uriel Hazan for

4 productive discussions, and all the members of the DIHP unit and Biolmage Analysis Group

5 for helpful interactions. VS was supported by a Ph.D. fellowship from the University Paris

6 Diderot attributed by the ENS Cachan, Université Paris-Saclay. JE is member of the LabEx

7 consortia IBEID and Milieulnterieur. JE also acknowledges support of from the ANR (grant

8 StopBugEntry and AutoHostPath) and the ERC (CoG EndoSubvert).

\section{Author contributions}

VS and JE designed the study and initiated the project. VS, JE and AD supervised the project. Salmonella infection were conducted by JV and VS. The automatic image analysis method was designed by VS, JV and AD. Flow cytometry measurements were achieved by IB and VS. The statistical analysis method was conceived by CG, JV and VS and performed by JV. VS and JE wrote the manuscript. JE provided the funding.

\section{Conflict of interest}

The authors declare that they have no conflict of interest. 
bioRxiv preprint doi: https://doi.org/10.1101/139048; this version posted May 17, 2017. The copyright holder for this preprint (which was not certified by peer review) is the author/funder, who has granted bioRxiv a license to display the preprint in perpetuity. It is made available under aCC-BY-NC-ND 4.0 International license.

A

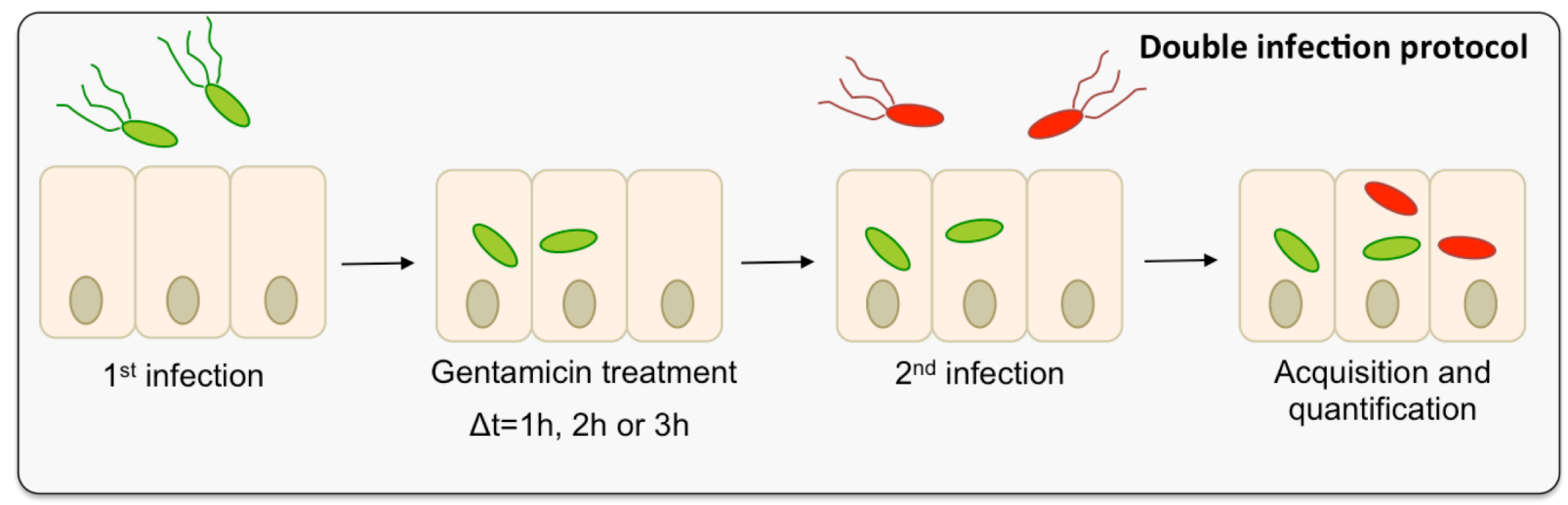

B

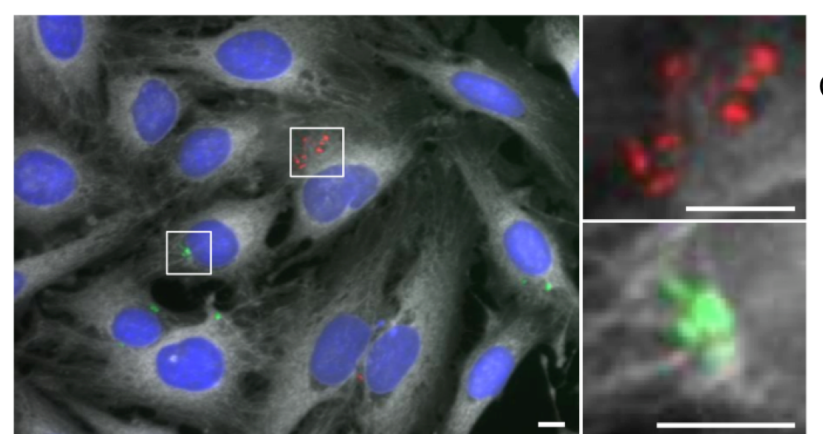

Automated acquisition (20X)

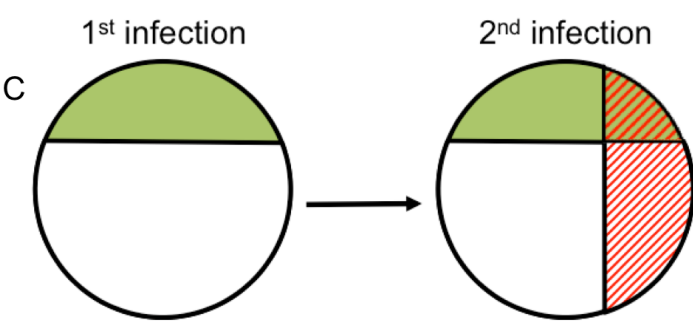

- 1 cells infected during the $1^{\text {st infection }}\left(I_{1}\right)$.

WIIA + पII cells infected during the $2^{\text {nd infection }}\left(\mathrm{I}_{2}\right)$.

cells infected during the $1^{\text {st }}$ and the $2^{\text {nd }}$ infection $\left(I_{1} \& I_{2}\right)$. cells never infected $\left(\mathrm{nol}_{1} \& \mathrm{nol}_{2}\right)$.
D

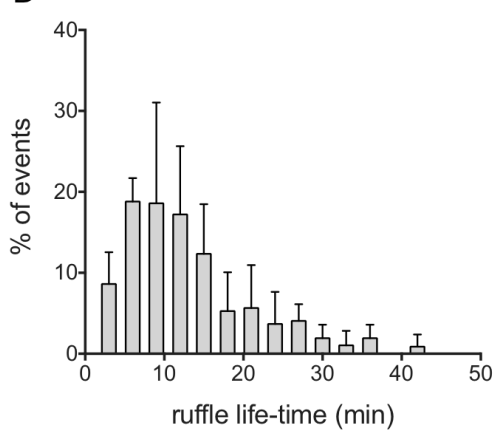

$E$

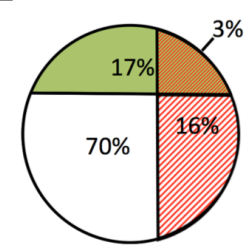

Independent model:

SLdsRed and

SLGFP infections are independents

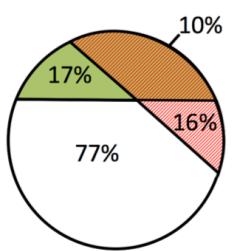

Data:

SLdsRed and SLGFP infections are NOT independents

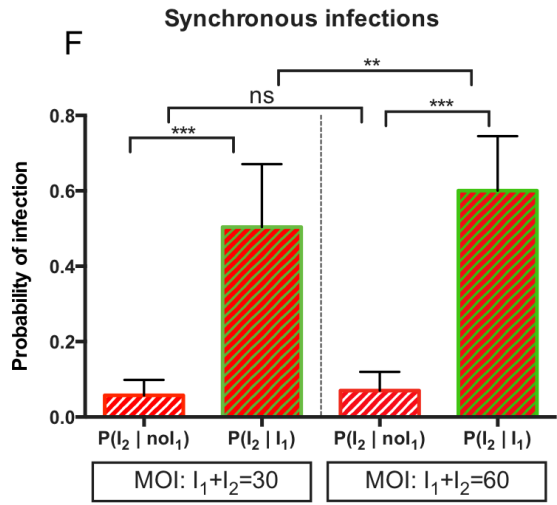

Fig.1. Double infections allow studies of Salmonella cooperation at the single cell level. A. B. C. Overview of the experimental workflow used in this study. A. Sequential infection protocol: HeLa cells grown in 96-wells plates since $24 \mathrm{~h}$ were subjected for $30 \mathrm{~min}$ to a first infection by $\mathrm{SL}_{G F P}$. This was followed by elimination of extracellular bacteria by gentamicin and incubation of the cells for 1,2 or $3 \mathrm{~h}$. The cells were subsequently challenged by a second infection with $\mathrm{SL}_{d s R e d}$ for $30 \mathrm{~min}$. After removal of the extracellular bacteria, the samples were fixed. Nuclei were stained with DAPI and cell membranes were stained with CellMask before microscopic acquisition of the entire wells. B. Representative image of $\mathrm{SL}_{G F P}$ and $\mathrm{SL}_{d s R e d}$ internalized in HeLa cells. Host cell nuclei are visible through DAPI (in blue), and cell membranes through CellMask (in grey). Scale bar correspond to $5 \mu \mathrm{m}$. C. Scheme of our statistical analysis of different subpopulations. The following cellular populations can be distinguished: those cells infected during the $1^{\text {st }}$ infection $\left(I_{1}\right)$ or not $\left(\mathrm{nol}_{1}\right)$, those infected during the $2^{\text {nd }}$ infection $\left(I_{2}\right)$ or not $\left(\mathrm{nol}_{2}\right)$, along with the related subpopulations $\left(I_{1} \& I_{2}, \mathrm{nol}_{1} \&\right.$ nol $\left.I_{2}\right)$. This scheme maps the case of two independent infections. D. Time distribution of the ruffle disappearance during Salmonella infection followed in actin-GFP transfected cells by time-lapse microscopy. E. Comparison of an independent model (left) with the obtained data (right). The percentages are averaged from 6 independent experiments, represented in $\mathbf{C}$ with an $\mathrm{MOI}$ of 30 . F. Comparison of the conditional probability of infection for two different populations during synchronous infection of $\mathrm{SL}_{G F P}$ and $\mathrm{SL}_{\text {dsRed }}$. The MOls were calculated after averaged CFU counting from 6 different experiments. P-values were obtained after paired t-test. 
A

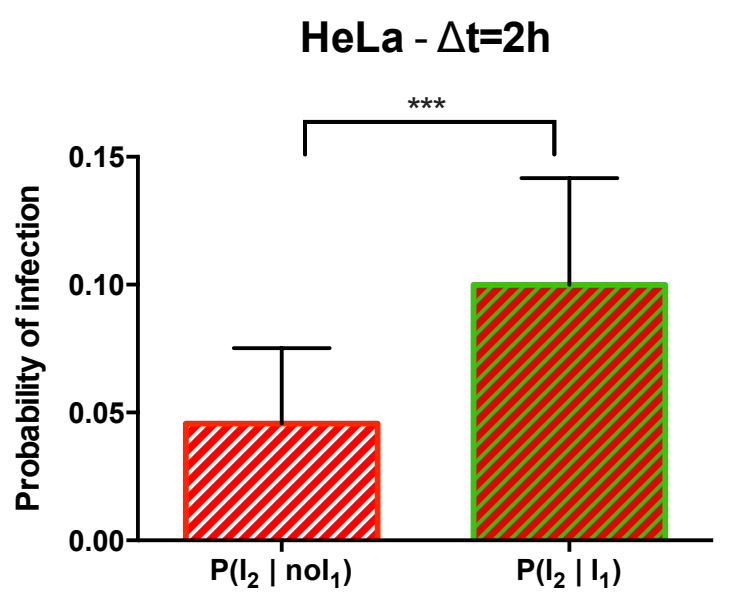

C

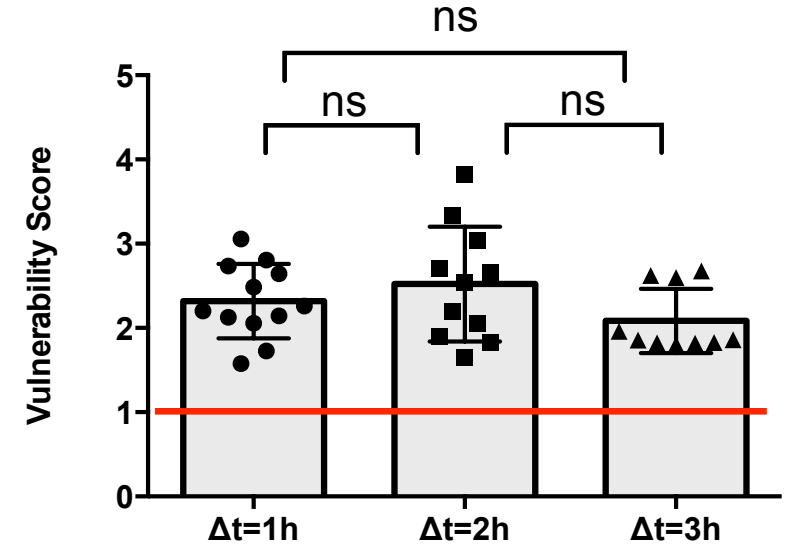

B

Caco-2 $-\Delta t=2 h$

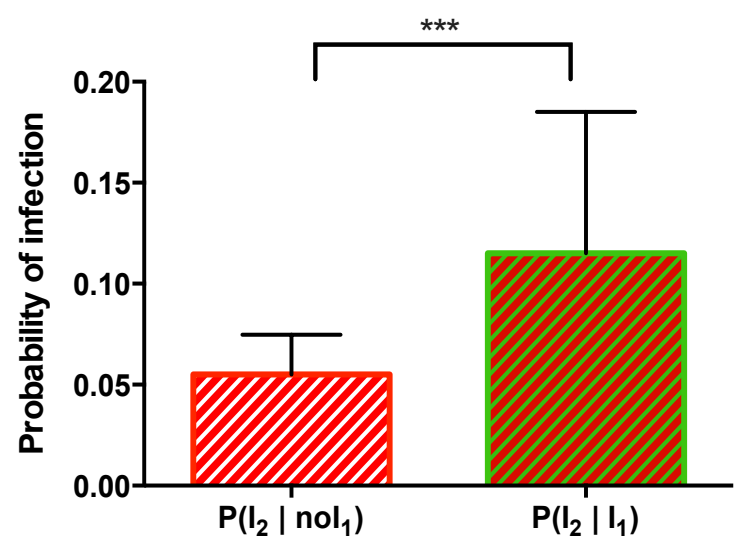

Fig.2. The probability of being re-infected by Salmonella remains higher for already infected cells after entry ruffle disappearance. A-B. Conditional probability of infection for two different populations during sequential infection with a delay of $2 \mathrm{~h}$ for HeLa cells (A) and Caco-2 cells (B). Results were obtained from 3 independent experiments and P-values were obtained after paired t-test. C. The vulnerability score was plotted for infection with a 1, 2 or 3 $h$ delay before the second infection. The red line corresponds to $\left.P\left(I_{2} \mid I_{1}\right)=P\left(I_{2} \mid \text { nol }\right)_{1}\right)=1$ indicating the independence of the infections $I_{2}$ and $I_{1}$. Values above the red line correspond to $\mathrm{P}\left(\mathrm{I}_{2} \mid \mathrm{I}_{1}\right)>\mathrm{P}\left(\mathrm{I}_{2} \mid\right.$ nol $\left._{1}\right)$ indicating a cooperation between infections. Values below the red line correspond to $P\left(I_{2} \mid I_{1}\right)<P\left(I_{2} \mid\right.$ noI $\left.I_{1}\right)$ indicating a competition between infections. Results were obtained from 3 independent experiments per time-point, and P-values were obtained after unpaired t-test. 


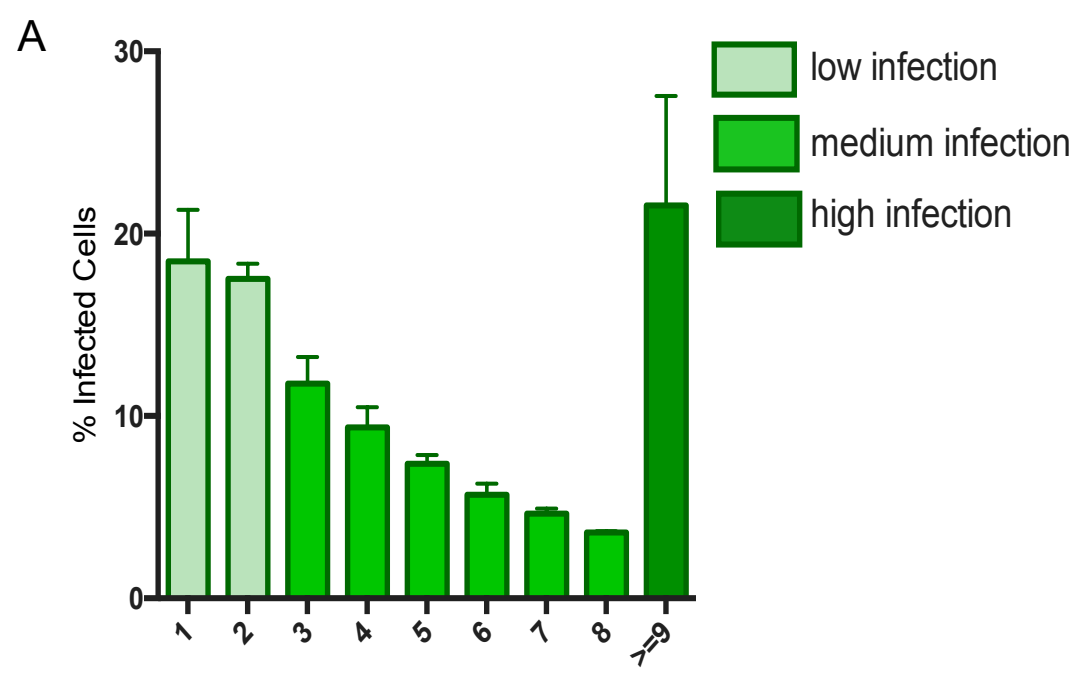

Number of intracellular bacteria

B

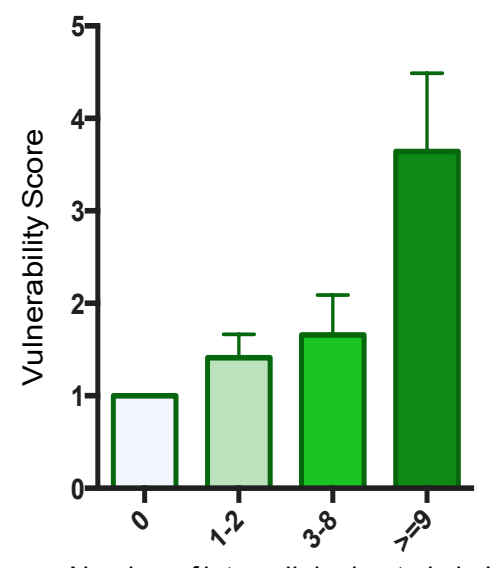

Number of intracellular bacteria in $\mathrm{I}_{1}$

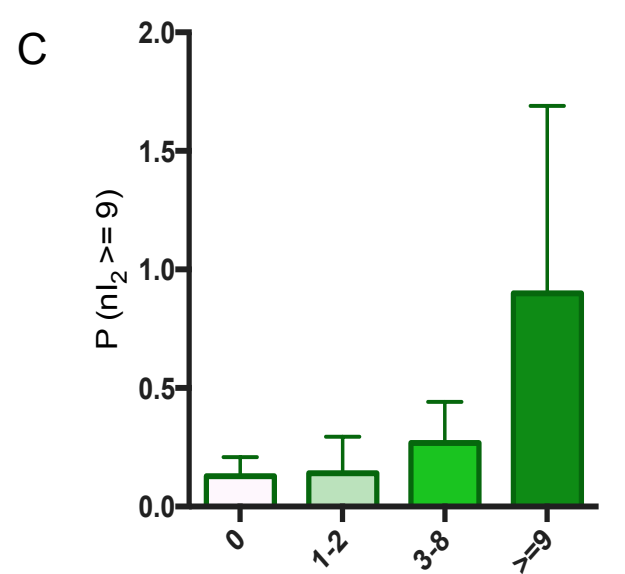

Number of intracellular bacteria in $\mathrm{I}_{1}$

Fig.3. Cell vulnerability can be predicted from the number of bacteria previously internalized. A. Distribution of the number of intracellular bacteria detected at $1.5 \mathrm{~h}$ pi (average from 3 replicates). The infection efficiencies are clustered in 3 groups: low, medium and high infection, corresponding respectively to 1 to $2 ; 3$ to 8 or more than 9 bacteria per cell. B. The vulnerability score is represented as a function of the number of intracellular bacteria resulting from the $1^{\text {st }}$ infection. C. Probability of a cell to be highly infected during the $2^{\text {nd }}$ infection $\left(\mathrm{nl}_{2}\right.$ $\geq 9$ ) as a function of the number of intracellular bacteria being internalized during the $1^{\text {st }}$ infection. $\mathbf{B}$ and $\mathbf{C}$ represent the data merged from all the experiments (delay of 1,2 and $3 \mathrm{~h}$ before the second infection). Groups of infection efficiency are identical in A, B and C. 
A
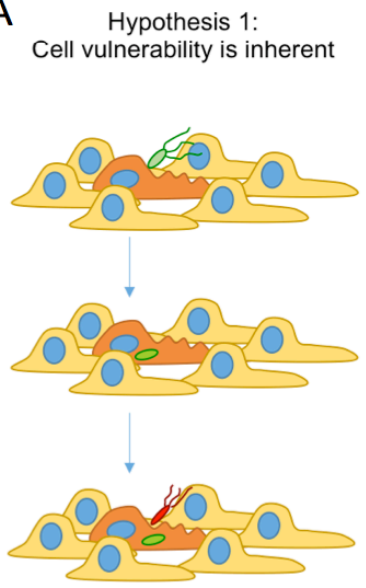

B

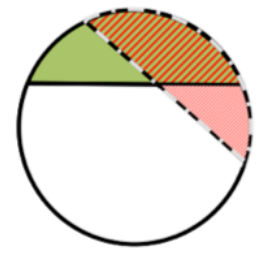

(1) Intrinsic vulnerability

$-\mathrm{I}_{2} \mid \mathrm{nol}_{1}<<\mathrm{I}_{2 \mathrm{ctr}}$
Hypothesis 2:

Cell vulnerability is induced by bacterial uptake

$1^{\text {st }}$ infection

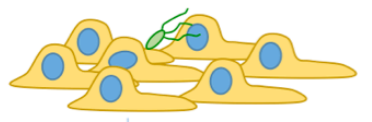

$\Delta \mathbf{t}$

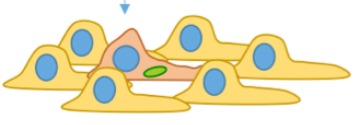

$2^{\text {nd }}$ infection

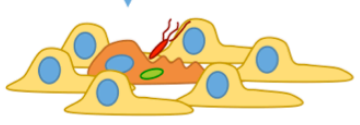

\section{C}

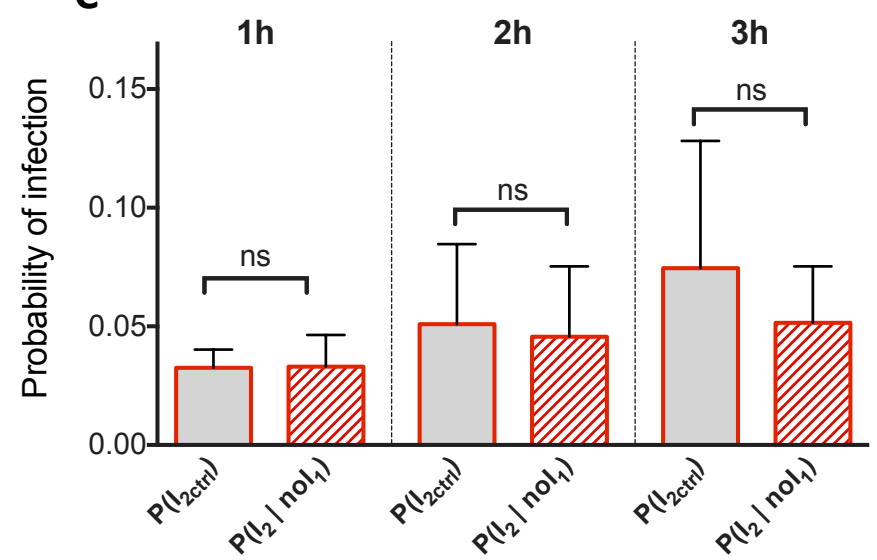

Fig.4. Cell vulnerability examined as an intrinsic or an induced property. A. Schemes of the two hypotheses for the origin of cell vulnerability. In the hypothesis 1 , cell vulnerability is inherent: some cells (in orange) are more vulnerable towards infection than other cells (in yellow). In the hypothesis 2 , cell vulnerability is induced by bacterial uptake: before infection cells are equal regarding their vulnerability (in yellow), but after infection the infected cells turn progressively more vulnerable (in orange). B. Graphic representation of the theoretical distribution of the different populations in the case of hypothesis 1 (left) or hypothesis 2 (right). C. Probability of infection during sequential infection with 1, 2 and $3 \mathrm{~h}$ delays for control cells $\left(\mathrm{I}_{2 \mathrm{Ctr}}\right)$ and cells non infected during the $1^{\text {st }}$ infection $\left(\mathrm{nol}_{1}\right)$. P-values were obtained after unpaired t-test $\left(\mathrm{P}\left(\mathrm{I}_{2 \mathrm{ctr}}\right)\right.$ vs $\left.\mathrm{P}\left(\mathrm{I}_{2} \mid \mathrm{noI}_{1}\right)\right)$. 
bioRxiv preprint doi: https://doi.org/10.1101/139048; this version posted May 17, 2017. The copyright holder for this preprint (which was

not certified by peer review) is the author/funder, who has granted bioRxiv a license to display the preprint in perpetuity. It is made

A
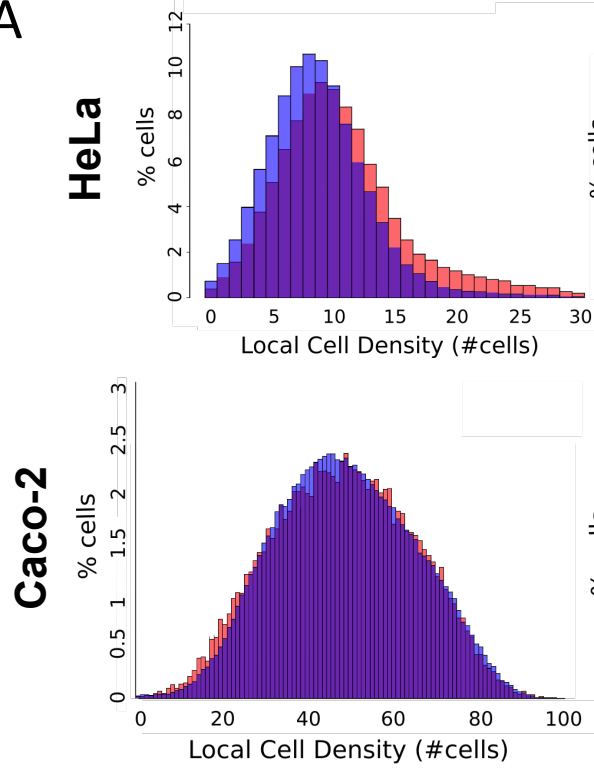
available under aCC-BY-NC-ND 4.0 International license.

B

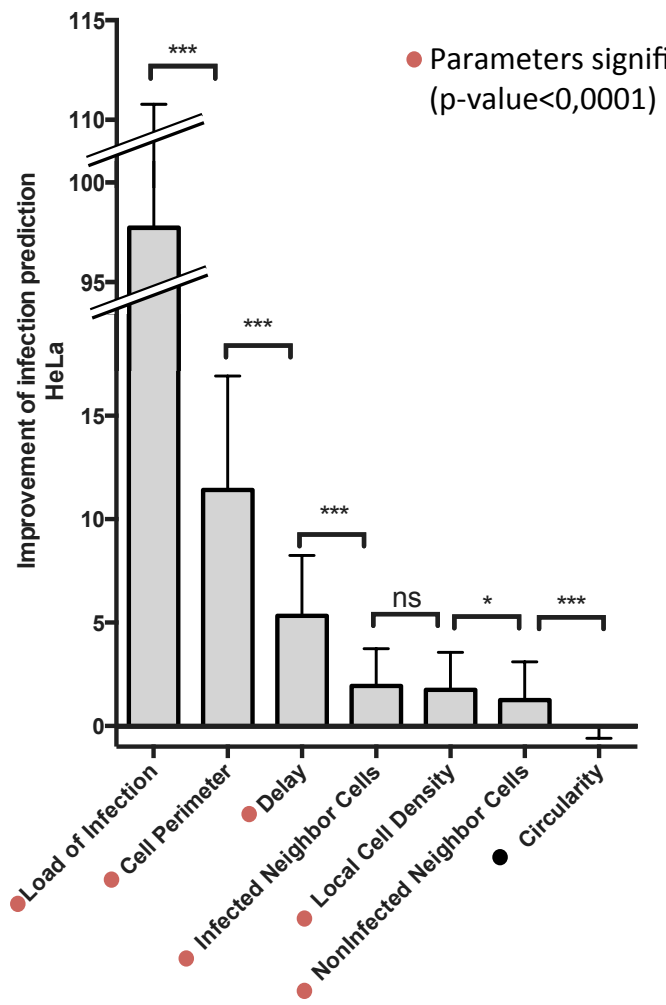

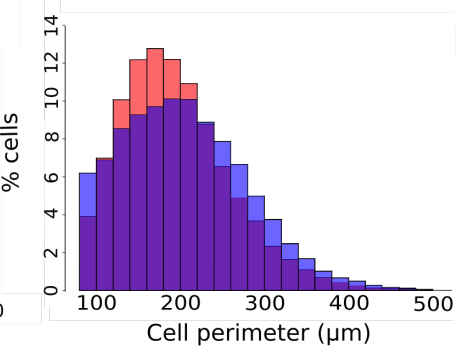

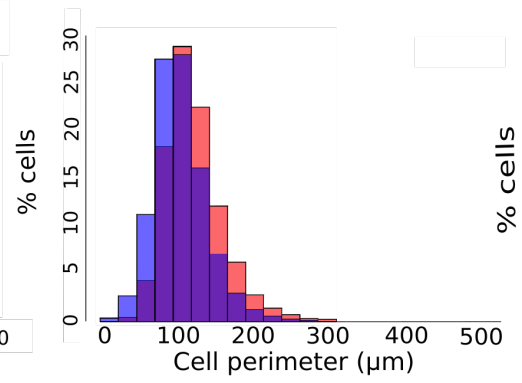

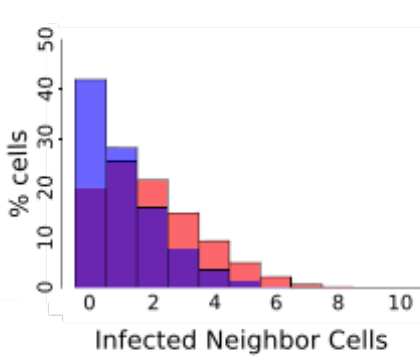
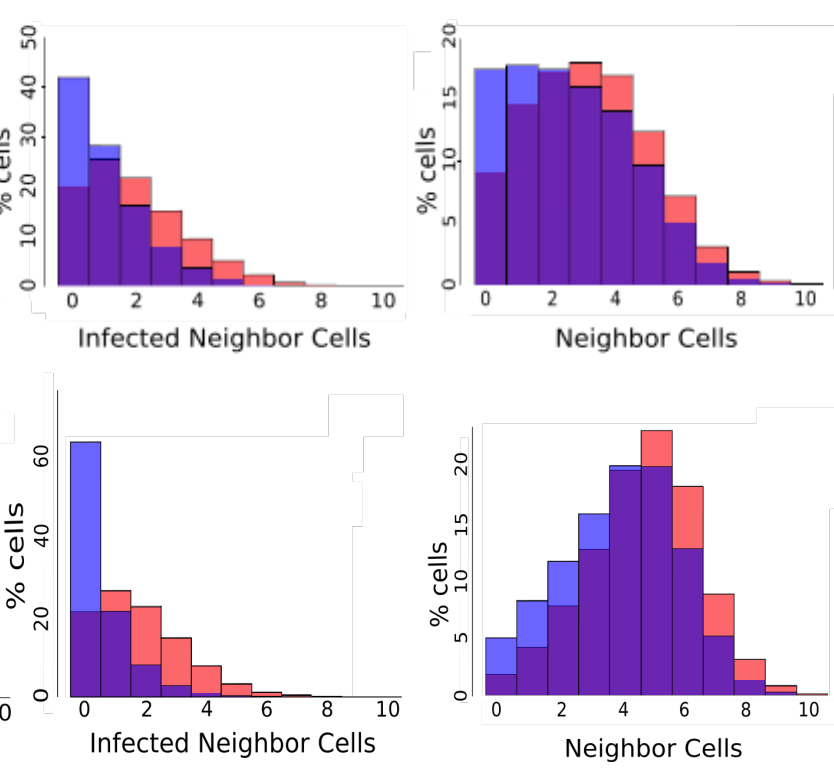

C

Fold change of the probability of infection

\begin{tabular}{|c|c|c|c|c|}
\hline $\begin{array}{c}\text { Inherent } \\
\text { vulnerability }\end{array}$ & low & low & high & high \\
\hline $\mathbf{1}^{\text {st }}$ infection & - & + & - & + \\
\hline HeLa & 1 & 2.2 & 1.6 & 3.3 \\
\hline Caco-2 & 1 & 1.3 & 2.6 & 3.3 \\
\hline
\end{tabular}

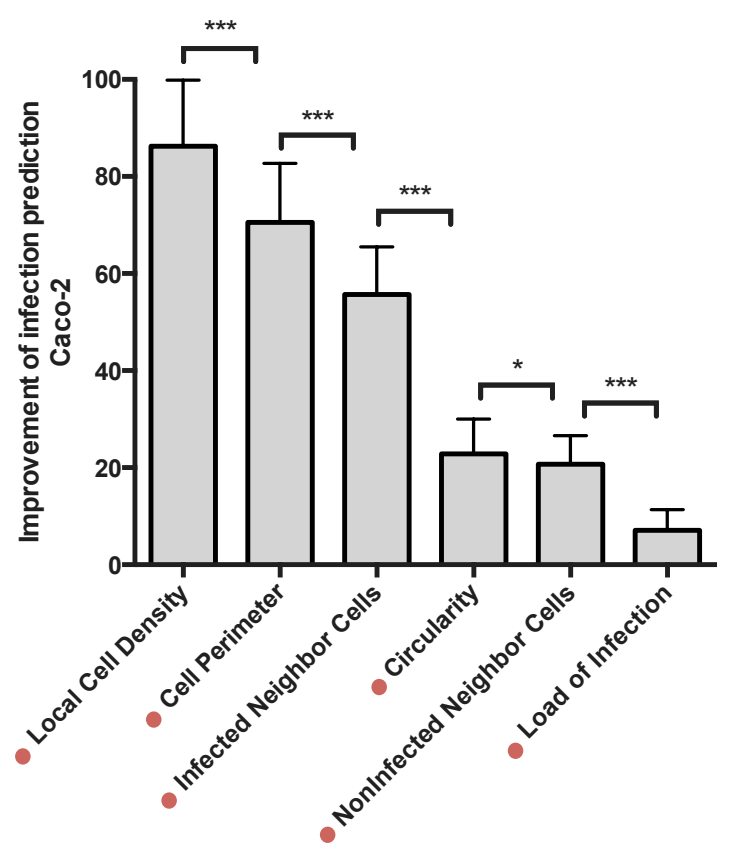

- Parameters not significant ( $p$-value $=0,9$ )
Non infected cells Infected cells

\begin{tabular}{|c|c|c|}
\hline $\begin{array}{c}\text { Change in P(inf) when } \\
\text { increased }\end{array}$ & HeLa & Caco-2 \\
\hline Cell size & $\boldsymbol{\lambda}$ & $\boldsymbol{\lambda}$ \\
\hline Circularity & $\boldsymbol{\imath}$ & $\boldsymbol{y}$ \\
\hline $\begin{array}{c}\text { Local cell density } \\
\text { Number of neighbor } \\
\text { cells }\end{array}$ & $\boldsymbol{\lambda}$ & $\boldsymbol{y}$ \\
\hline $\begin{array}{c}\text { Number of infected } \\
\text { neighbor cells }\end{array}$ & $\boldsymbol{\lambda}$ & $\boldsymbol{\lambda}$ \\
\hline $\begin{array}{c}\text { Load of infection } \\
\text { Lom }\end{array}$ & $\boldsymbol{\lambda}$ & $\boldsymbol{\lambda}$ \\
\hline
\end{tabular}


Fig.5. Single cell vulnerability to Salmonella infection is a combination of intrinsic and induced vulnerability. A. The depicted cellular parameters were determined for HeLa cells (upper panel) and Caco-2 cells (lower panel) as described in detail in Materials and Methods. An overlay of the distribution of some of these parameters in infected (red) or non-infected (blue) cells is shown. B. Quantification of the improvement of infection prediction by each cell parameters by subtracting the likelihood (in log) of the model including all parameters from a model ignoring one parameter. Results are averaged over 100 training/testing circles for each model. P-values were obtained after paired t-test. C. Fold change of the probability of infection as a function of the intrinsic vulnerability and of a previous infection. D. Increasing or decreasing of the probability of infection when the listed cell parameters increase their values. 
A

Probability of infection

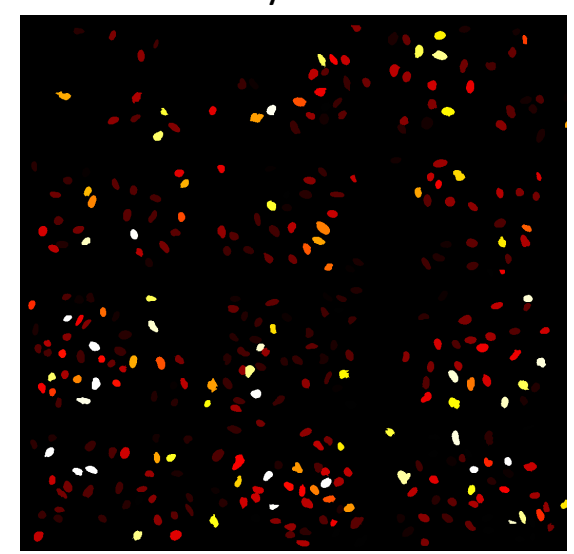

Model-based probability of infection
Measured infection

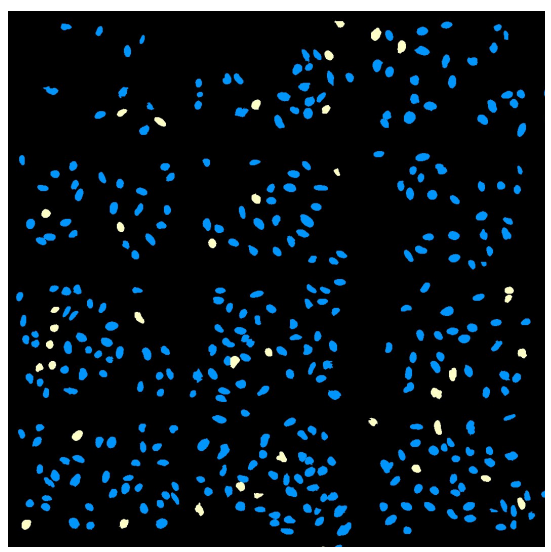

$\square$ Non infected cells

Infected cells

B

\begin{tabular}{|c|c|c|}
\hline $\begin{array}{c}\text { Model } \\
\text { predictions }\end{array}$ & HeLa & Caco-2 \\
\hline True & $62 \%$ & $66 \%$ \\
\hline False & $38 \%$ & $34 \%$ \\
\hline
\end{tabular}

Fig.6. Comparison of model-predicted vulnerability of single-cell with measured-infection. A. Model-predicted probability of infection displayed on reproduced original images of HeLa cells (left panel). Colors are adapted for maximum contrast between lowest (deep red) and highest (white) probability of infection. Measured infections from experiments are shown (top-right panel). B. Estimation of the reliability of the two (HeLa and Caco-2) models developed when tested on a total of 100 infected cells and 100 non-infected cells. 


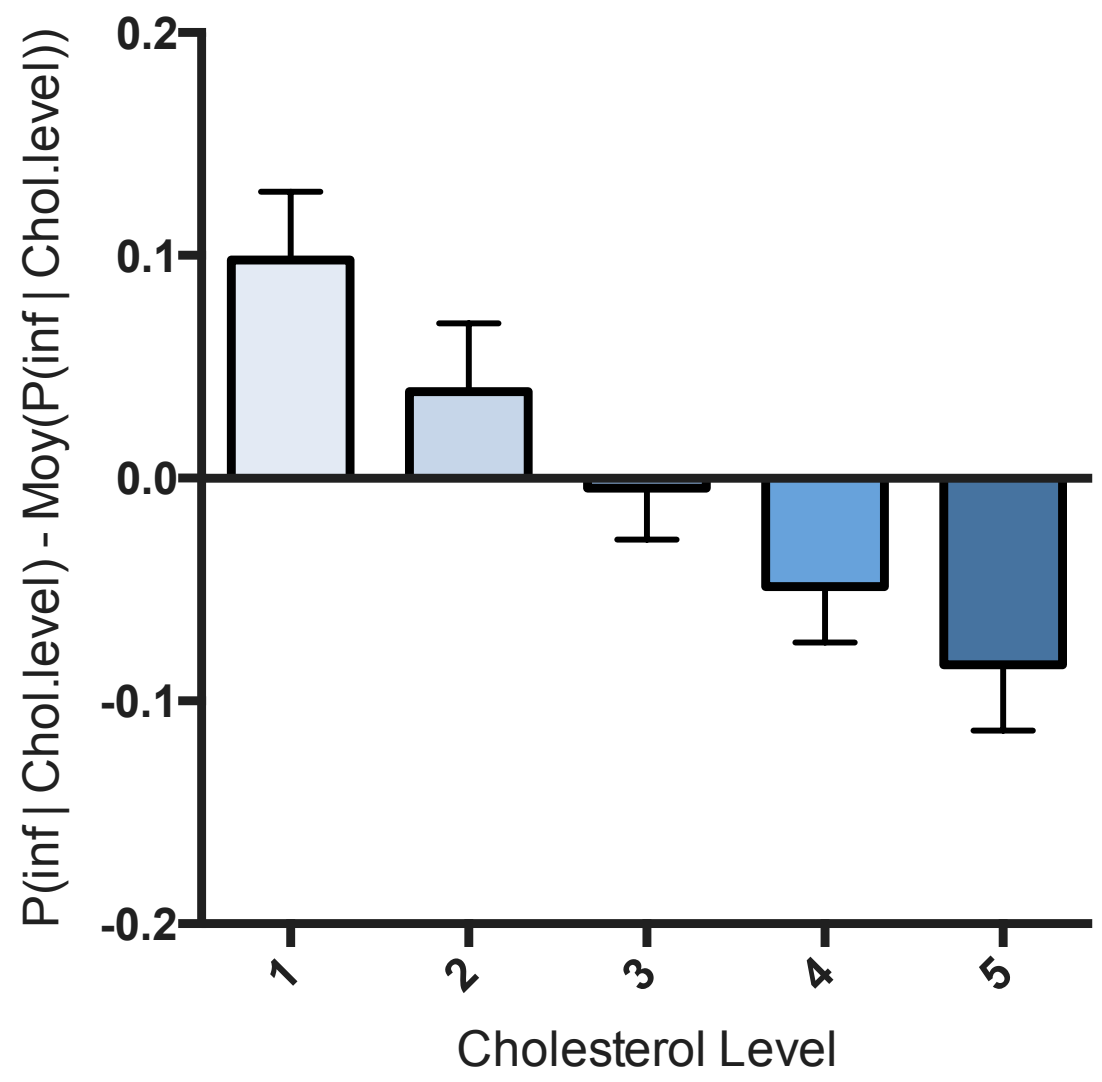

Fig.7. Probability of infection as a function of single cell cholesterol level. Variation of the probability of Salmonella infection at different levels of host cholesterol measured by FACS as described in detail in the text. Cholesterol levels were binned in five categories at $20 \%$ steps from lowest to highest levels over the total cell population, each category contains $20 \%$ of the whole cells. Results are averaged over 3 independent experiments. 
bioRxiv preprint doi: https://doi.org/10.1101/139048; this version posted May 17, 2017. The copyright holder for this preprint (which was

not certified by peer review) is the author/funder, who has granted bioRxiv a license to display the preprint in perpetuity. It is made available under aCC-BY-NC-ND 4.0 International license.

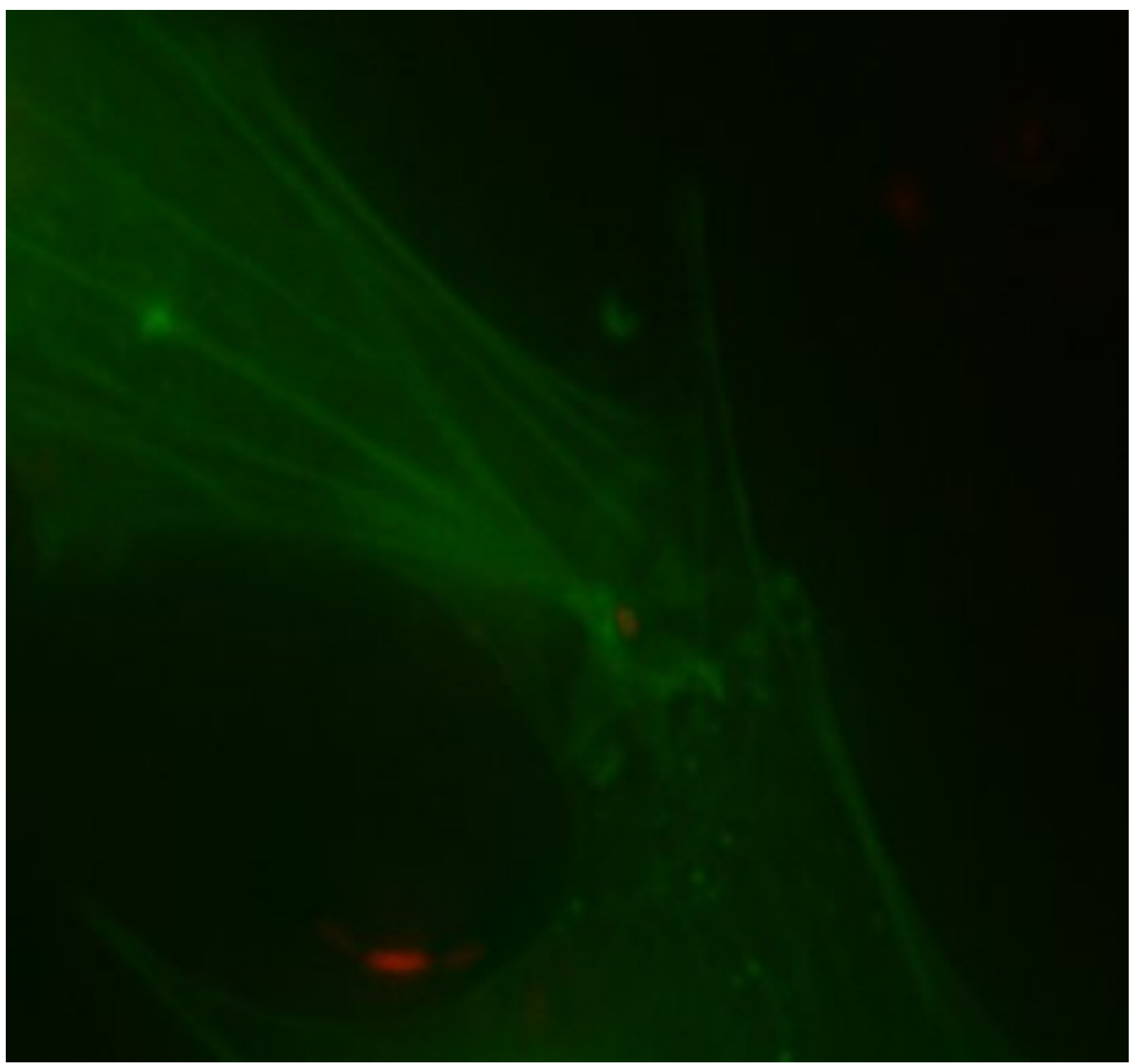

Video.S1. Ruffle appearance and disappearance after entry of single salmonellae in a host cell. Time intervals between the frames are $3 \mathrm{~min}$. The green channel corresponds to actin-GFP transfected cells and shows the membrane ruffles. The red channel shows salmonellae $\mathrm{SL}_{d s \text { Red }}$. 
bioRxiv preprint doi: https://doi.org/10.1101/139048; this version posted May 17, 2017. The copyright holder for this preprint (which was

not certified by peer review) is the author/funder, who has granted bioRxiv a license to display the preprint in perpetuity. It is made available under aCC-BY-NC-ND 4.0 International license.

Video.S2. Ruffle appearance and disappearance after entry of multiple salmonellae in a host cell. Time intervals between the frames are $3 \mathrm{~min}$. The green channel corresponds to actin-GFP transfected cells and shows the membrane ruffles. The red channel shows salmonellae $\mathrm{SL}_{\text {dsRed }}$. 


\begin{tabular}{|c|c|c|c|c|}
\hline Cell line: HeLa & Coefficient & Standard Error & $\begin{array}{l}\text { Difference of } \\
\text { LogLikelihood }\end{array}$ & $\begin{array}{l}\text { p-value on difference } \\
\text { of LogLikelihood }\end{array}$ \\
\hline Intercept & -4.231 & 0.169 & & \\
\hline Low 1st Infection & 0.385 & 0.033 & \multirow{3}{*}{97.725} & \multirow{3}{*}{$5.99 E-52$} \\
\hline Medium 1st Infection & 0.765 & 0.031 & & \\
\hline High 1st Infection & 1.461 & 0.0322 & & \\
\hline Infected neighbor cells & 0.055 & 0.009 & 1.941 & $2.01 \mathrm{E}-18$ \\
\hline Non-infected neighbor cells & -0.053 & 0.01 & 1.25 & $1.10 \mathrm{E}-09$ \\
\hline Local cell density & 0.018 & 0.003 & 1.752 & $6.07 E-16$ \\
\hline Cell perimeter & 0.004 & 0.000 & 11.409 & $9.27 E-38$ \\
\hline Circularity & 0.198 & 0.167 & -0.008 & 8.89E-01 \\
\hline Delay-2h & 0.155 & 0.029 & \multirow{2}{*}{5.332} & \multirow{2}{*}{$1.57 \mathrm{E}-33$} \\
\hline Delay-3h & 0.304 & 0.03 & & \\
\hline
\end{tabular}

Table.S1. Model coefficient values for HeLa cells with the corresponding standard error for each cell parameter. Difference of log-likelihood obtained after subtraction of the loglikelihood of the model including all parameters from the log-likelihood of a model ignoring one parameter (see graphic representation in Fig.5B). The presented values were averaged with the values obtained over 100 training/testing circles for each model. P-values were obtained after paired t-test. 


\begin{tabular}{|c|c|c|c|c|}
\hline Cell line: Caco-2 & Coefficient & Standard Error & \begin{tabular}{|c|} 
Difference of \\
LogLikelihood
\end{tabular} & $\begin{array}{l}\text { p-value on difference } \\
\text { of LogLikelihood }\end{array}$ \\
\hline Intercept & -0.48 & 0.14 & & \\
\hline Low 1st Infection & 0.25 & 0.02 & \multirow{3}{*}{7.07} & \multirow{3}{*}{$2.29 \mathrm{E}-30$} \\
\hline Medium 1st Infection & 0.23 & 0.03 & & \\
\hline High 1st Infection & 0.20 & 0.06 & & \\
\hline Infected neighbor cells & 0.23 & 0.01 & 55.69 & $3.28 \mathrm{E}-77$ \\
\hline Non-infected neighbor cells & 0.09 & 0.00 & 20.71 & $7.75 \mathrm{E}-58$ \\
\hline Local cell density & -0.02 & 0.00 & 86.25 & $6.70 \mathrm{E}-82$ \\
\hline Cell perimeter & 0.01 & 0.00 & 70.56 & $2.52 \mathrm{E}-78$ \\
\hline Circularity & -2.96 & 0.14 & 22.83 & $1.26 \mathrm{E}-53$ \\
\hline
\end{tabular}

Table.S2. Model coefficient values for Caco-2 cells with the corresponding standard error for each cell parameter. Difference of log-likelihood obtained after subtraction of the loglikelihood of the model including all parameters from the log-likelihood of a model ignoring one parameter (see graphic representation in Fig.5B). The presented values were averaged with the values obtained over 100 training/testing circles for each model. P-values were obtained after paired t-test. 


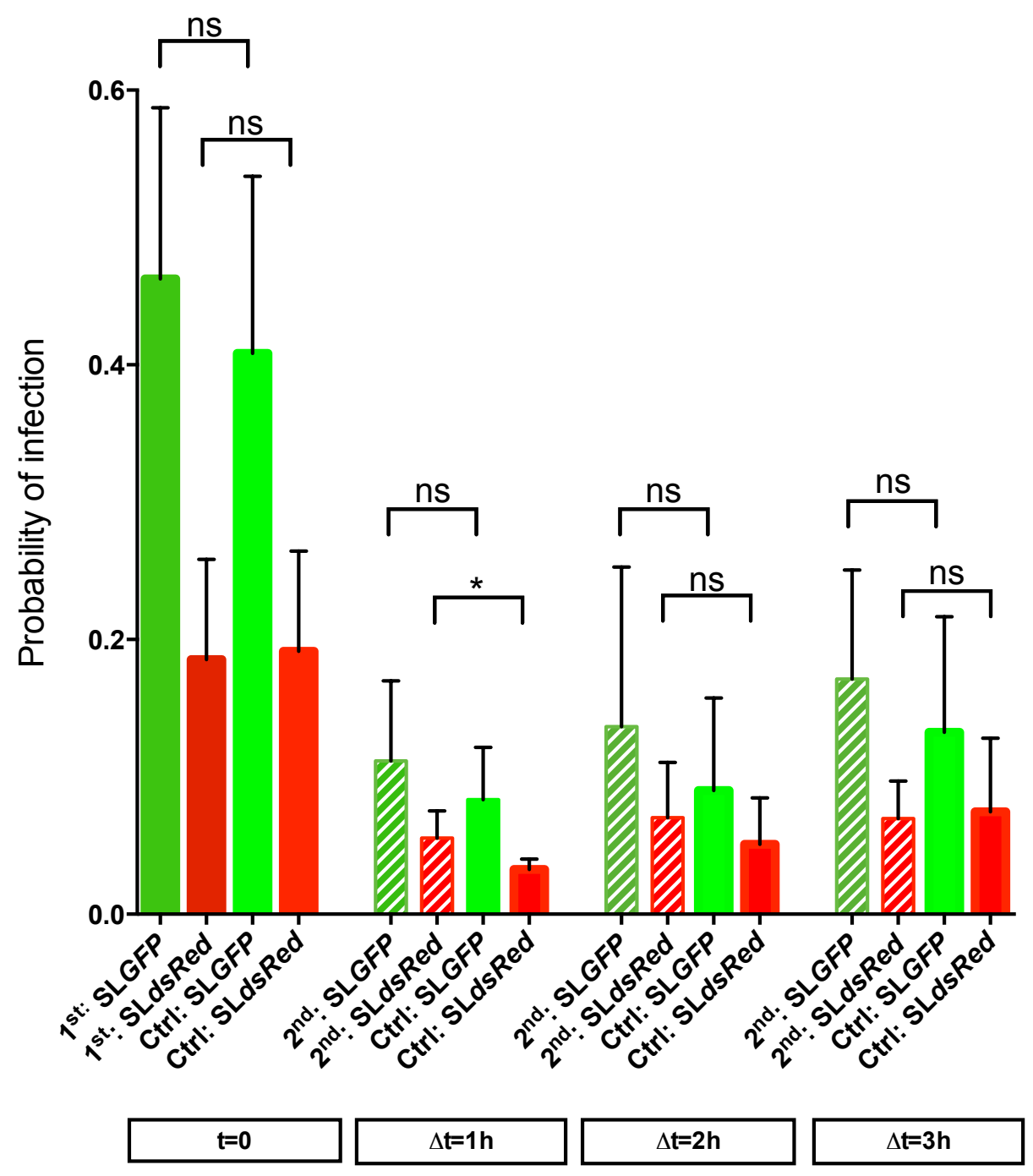

Fig.S1. Probability of $\mathrm{SL}_{G F P}$ and $\mathrm{SL}_{\text {dsRed }}$ infections at different time-points after the beginning of cell challenge $(\mathrm{t}=0)$ between single (control) or sequential infections. 

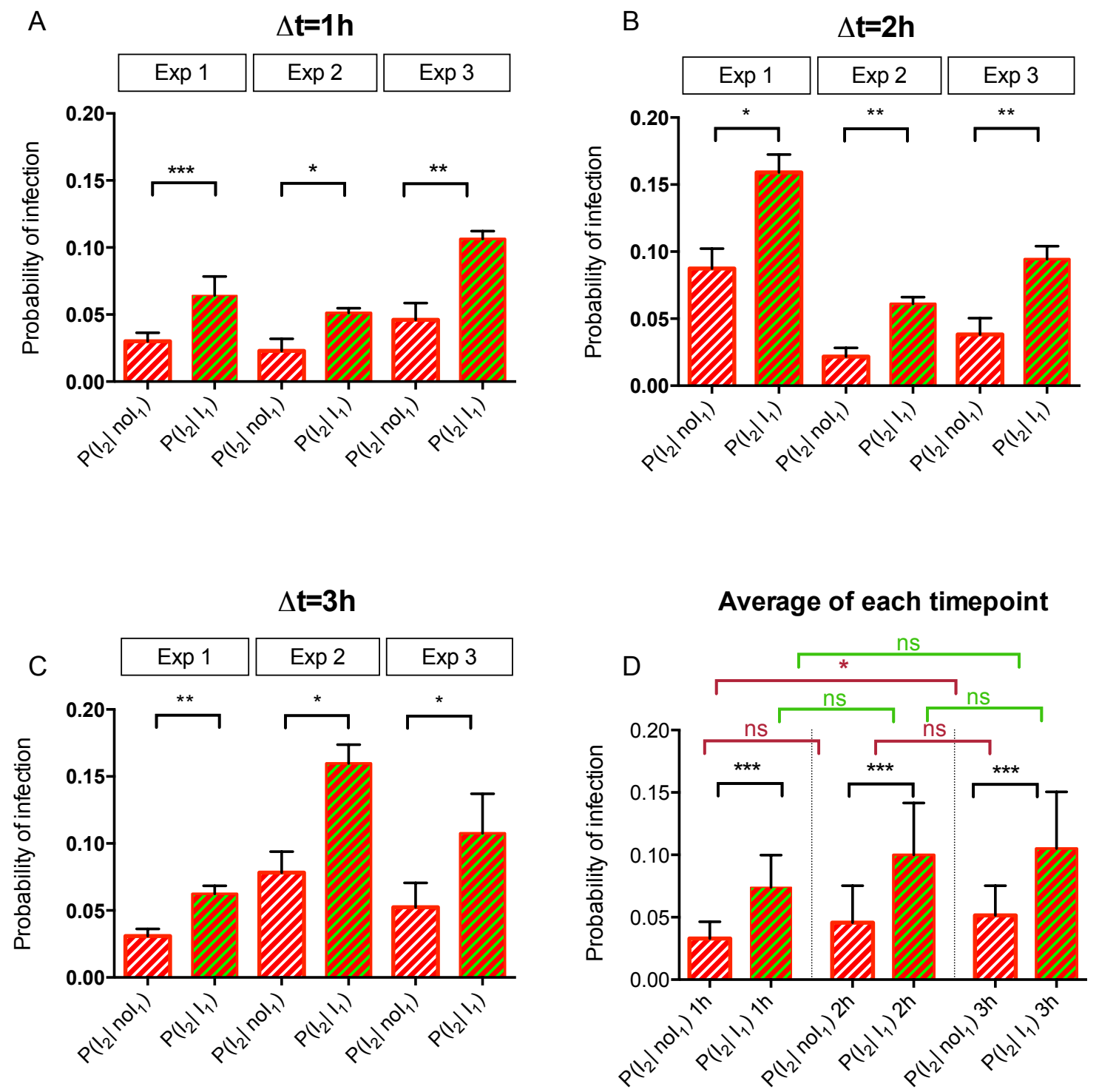

Fig.S2. A.B.C. Detailed depiction of the conditional probability of infection for two different populations during sequential infection with a delay of $1 \mathrm{~h}(\mathbf{A}), 2 \mathrm{~h}(\mathrm{~B})$ and $3 \mathrm{~h}(\mathrm{C})$ for each independent experiment with 3 replicates per experiment. P-values were obtained after paired t-test. D. Representation of the results from A, B and $\mathbf{C}$ after averaging them for each delay. Pvalues were obtained after paired $\mathrm{t}$-test. The $\mathrm{P}$-values in black resulted from a t-test comparing $\mathrm{P}\left(\mathrm{I}_{2} \mid \mathrm{I}_{1}\right)$ and $\mathrm{P}\left(\mathrm{I}_{2} \mid\right.$ nol $\left._{1}\right)$. The P-values in red resulted from a t-test comparing $\mathrm{P}\left(\mathrm{I}_{2} \mid\right.$ nol $\left.\mathrm{I}_{1}\right)$ for $1 \mathrm{~h}$ versus $2 \mathrm{~h}$ and $2 \mathrm{~h}$ versus $3 \mathrm{~h}$. The P-values in green resulted from a t-test comparing $P\left(I_{2} \mid I_{1}\right)$ for $1 \mathrm{~h}$ versus $2 h$ and $2 h$ versus $3 h$. 


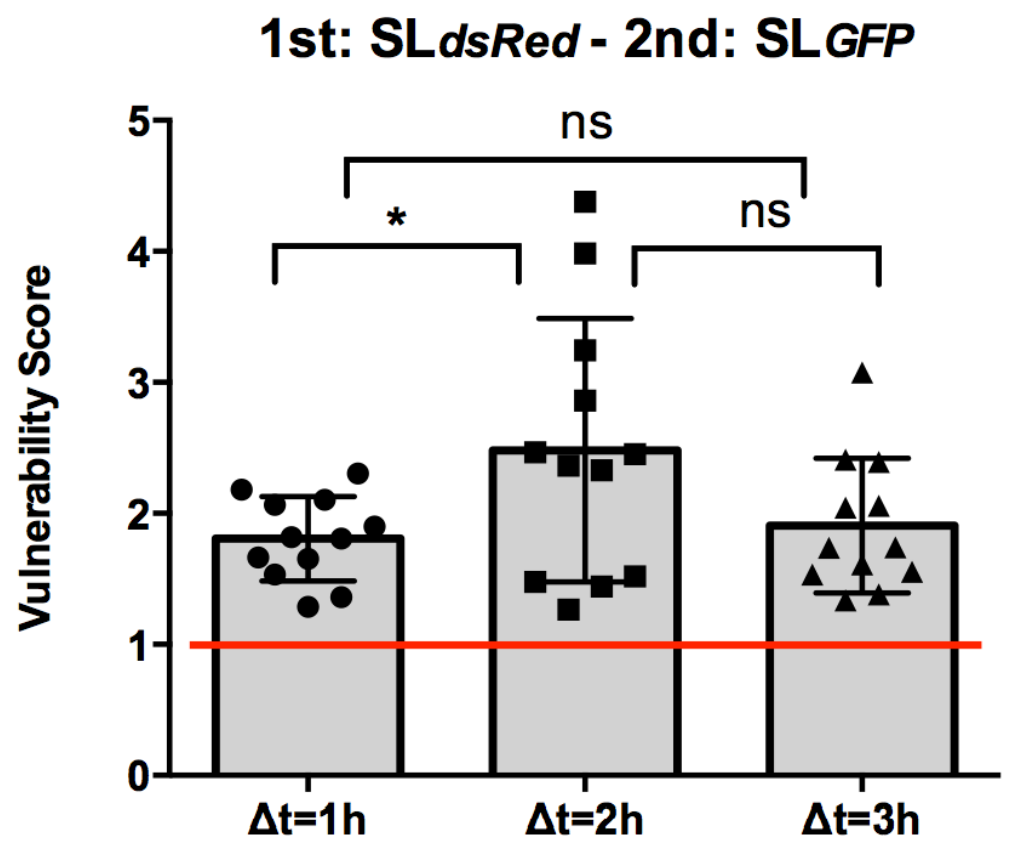

Fig.S3. Vulnerability scores for the inverted infections compared to Fig.2C ( $S L_{\text {dsRed }}$ before $\mathrm{SL}_{G F P}$ ) with a delay of 1,2 and $3 \mathrm{~h}$ between infections. The red line corresponds to $P\left(I_{2} \mid I_{1}\right)=P\left(I_{2} \mid\right.$ nol $\left._{1}\right)=1$ indicating the independence of the infections $I_{2}$ and $I_{1}$. Values above the red line correspond to $\mathrm{P}\left(\mathrm{I}_{2} \mid \mathrm{I}_{1}\right)>\mathrm{P}\left(\mathrm{I}_{2} \mid\right.$ noI $\left._{1}\right)$ indicating a cooperation between infections. Values below the red line correspond to $P\left(I_{2} \mid I_{1}\right)<P\left(I_{2} \mid\right.$ nol $\left.{ }_{1}\right)$ indicating a competition between infections. Results were obtained from 3 independent experiments per time-point, and P-values were obtained after unpaired t-test. 


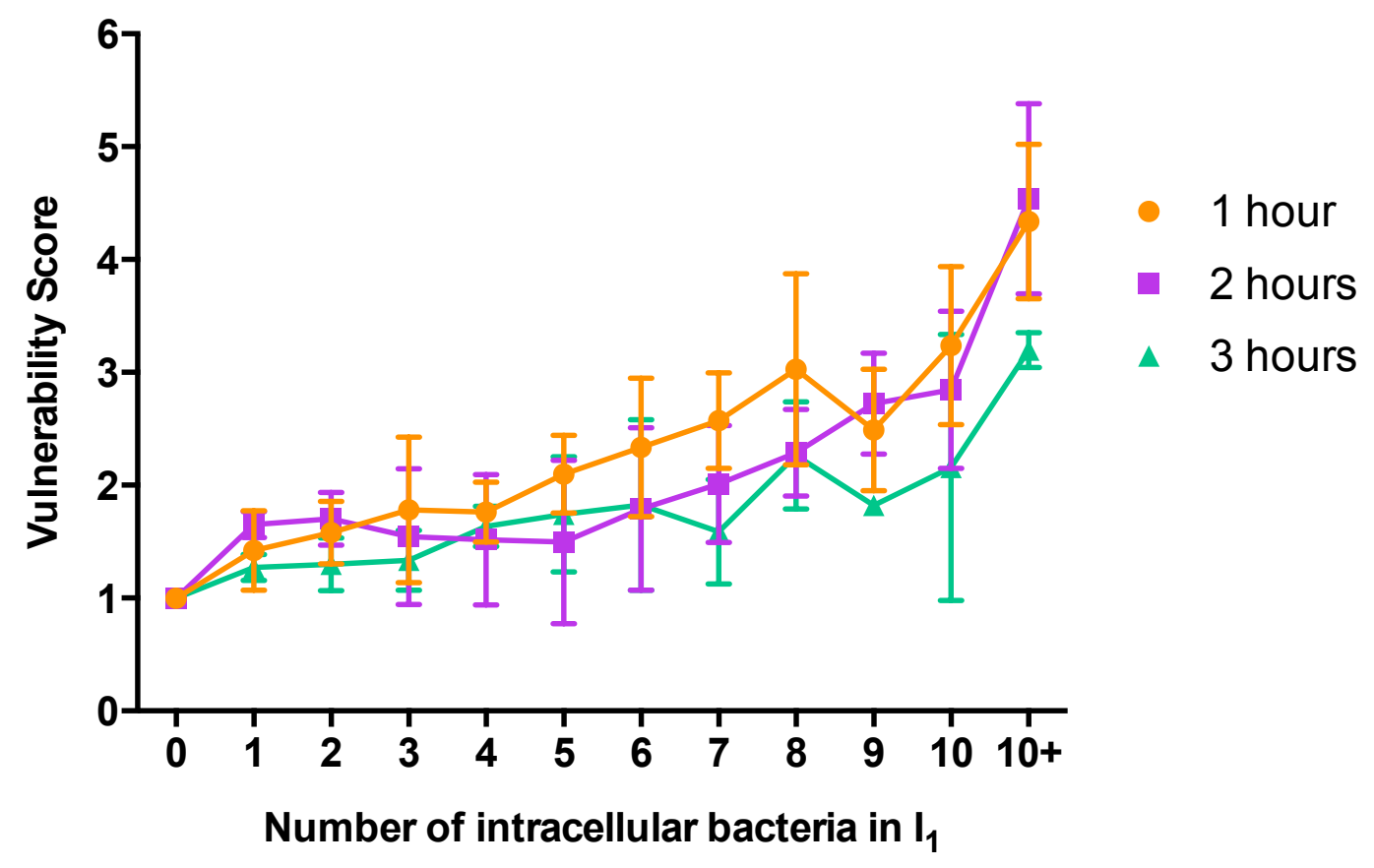

Fig.S4. Vulnerability score as a function of the number of intracellular bacteria resulting from the $1^{\text {st }}$ infection with a delay of 1,2 and $3 \mathrm{~h}$ between the infections. Results were obtained from 3 independent experiments per time-point. 
A.

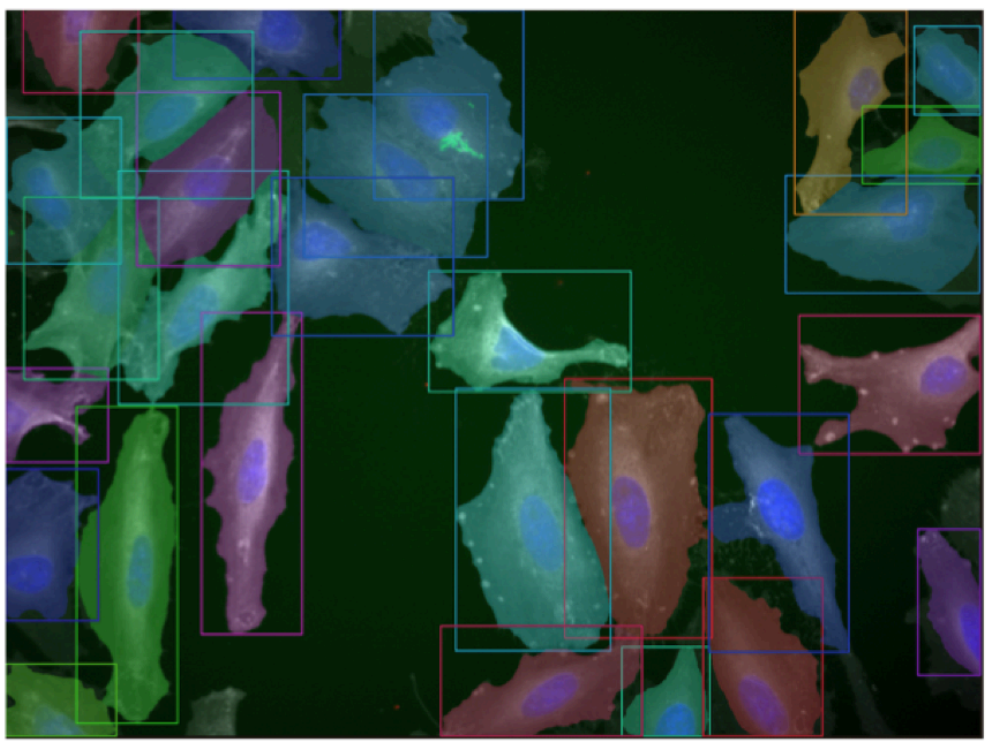

Icy automated cell detection

B.

HeLa

\begin{tabular}{|c|c|c|c|c|c|c|c|c|c|}
\hline Correlations & 2nd Infection & $\begin{array}{c}\text { Load of } \\
\text { Infection }\end{array}$ & $\begin{array}{c}\text { Infected } \\
\text { neighbor cells }\end{array}$ & $\begin{array}{c}\text { Non-infected } \\
\text { neighbor cells }\end{array}$ & Neighbor cells & $\begin{array}{c}\text { Local cell } \\
\text { density }\end{array}$ & Cell perimeter & vCircularity & Delay \\
\hline 2nd Infection & & & & & & & & & \\
\hline Load of Infection & 0.15 & & & & & & & & \\
\hline Infected neighbor cells & 0.07 & 0.27 & & & & & & & \\
\hline Non-infected neighbor cells & -0.01 & -0.12 & -0.07 & & & & & & \\
\hline Neighbor cells & 0.04 & 0.12 & 0.72 & 0.64 & & & & & \\
\hline Local cell density & 0.02 & 0.16 & 0.52 & 0.05 & 0.43 & & & & \\
\hline Cell perimeter & 0.05 & -0.06 & 0.05 & 0.33 & 0.26 & -0.36 & & & \\
\hline vCircularity & -0.03 & 0.05 & -0.01 & -0.09 & -0.06 & 0.28 & -0.68 & & \\
\hline Delay & 0.02 & -0.09 & -0.27 & 0.07 & -0.16 & -0.21 & 0.06 & -0.02 & \\
\hline
\end{tabular}

C.

Caco-2

\begin{tabular}{|c|c|c|c|c|c|c|c|c|c|}
\hline Correlations & 2nd Infection & $\begin{array}{c}\text { Load of } \\
\text { Infection }\end{array}$ & $\begin{array}{c}\text { Infected } \\
\text { neighbor cells }\end{array}$ & $\begin{array}{c}\text { Non-infected } \\
\text { neighbor cells }\end{array}$ & Neighbor cells & $\begin{array}{c}\text { Local cell } \\
\text { density }\end{array}$ & Cell perimeter & Circularity & Replicate \\
\hline 2nd Infection & & & & & & & & & \\
\hline Load of Infection & 0.08 & & & & & & & & \\
\hline Infected neighbor cells & 0.11 & 0.40 & & & & & & & \\
\hline Non-infected neighbor cells & 0.07 & -0.10 & -0.20 & & & & & & \\
\hline Neighbor cells & 0.12 & 0.12 & 0.34 & 0.85 & & & & & \\
\hline Local cell density & -0.13 & -0.02 & 0.00 & 0.03 & 0.03 & & & & \\
\hline Cell perimeter & 0.21 & 0.16 & 0.21 & 0.42 & 0.52 & -0.37 & & & \\
\hline Circularity & -0.15 & -0.13 & -0.22 & -0.36 & -0.46 & 0.13 & -0.57 & & \\
\hline Replicate & 0.00 & 0.04 & 0.13 & -0.12 & -0.05 & 0.36 & -0.27 & 0.12 & \\
\hline
\end{tabular}

$-1$

$-0.75$

$-0.5$

$-0.25$

0.25

0.5

0.75

1

Fig.S5. Cell parameter correlations. A. Illustration of Icy cell segmentation using Active Contours (see Materials and Methods for plugins detail). B-C. Table of the correlations between the different cell parameters for HeLa (B) and Caco-2 (C) cells. 
bioRxiv preprint doi: https://doi.org/10.1101/139048; this version posted May 17,2017 . The copyright holder for this preprint (which was

not certified by peer review) is the author/funder, who has granted bioRxiv a license to display the preprint in perpetuity. It is made available under aCC-BY-NC-ND 4.0 International license.

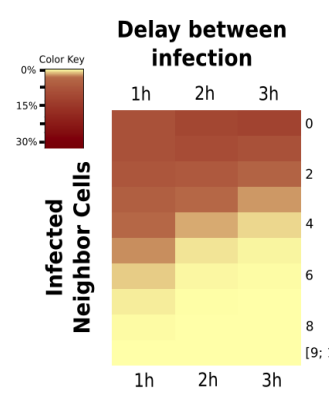

\section{HeLa}
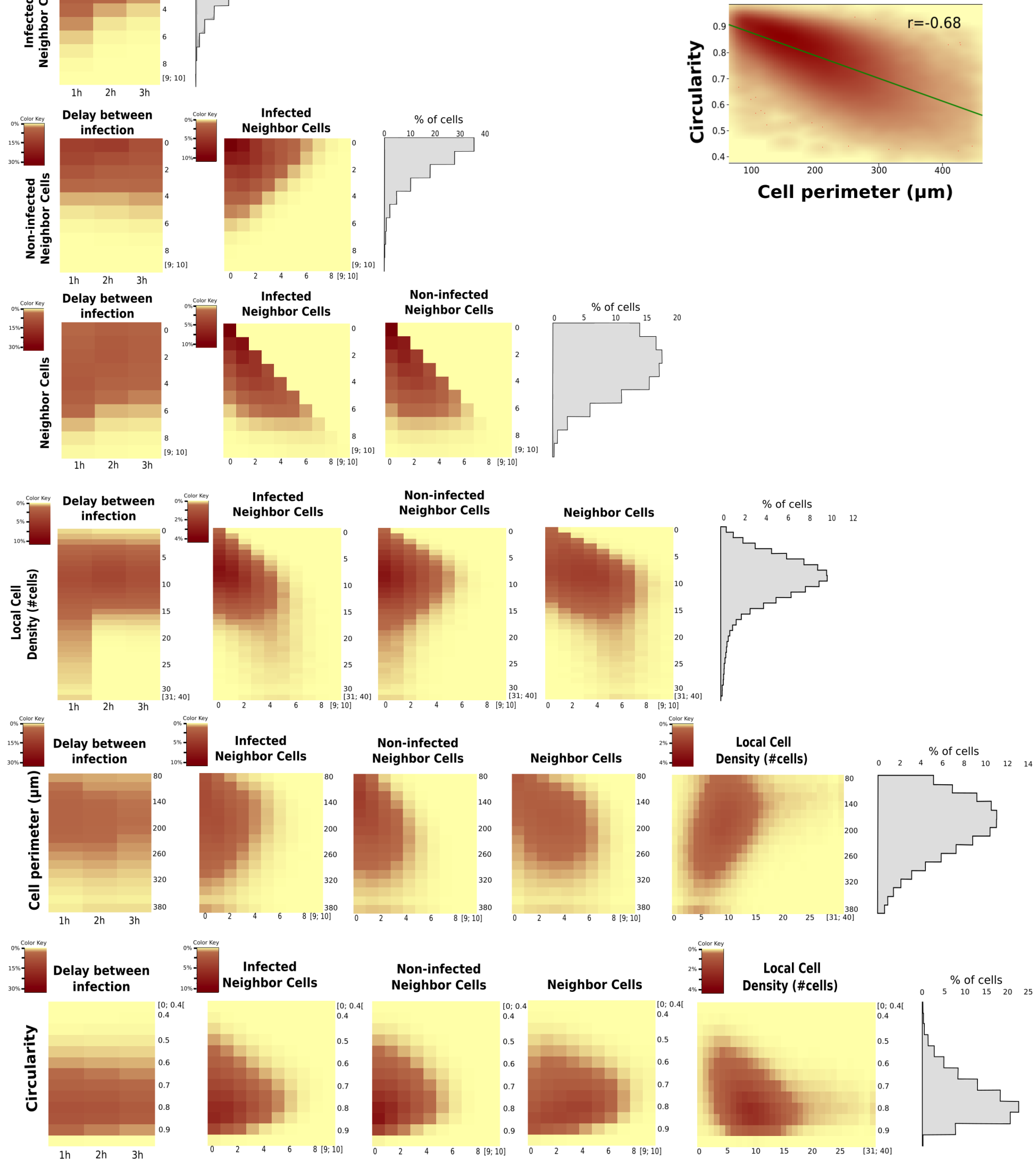

Fig.S6. Scatter plot and heat-map of the different cell parameters studied in HeLa cells model allowing to evaluate the relation between these parameters. Grey histograms represent the distribution of the vertical axe parameter in the entire cell population. 
bioRxiv preprint doi: https://doi.org/10.1101/139048; this version posted May 17,2017 . The copyright holder for this preprint (which was

not certified by peer review) is the author/funder, who has granted bioRxiv a license to display the preprint in perpetuity. It is made available under aCC-BY-NC-ND 4.0 International license.

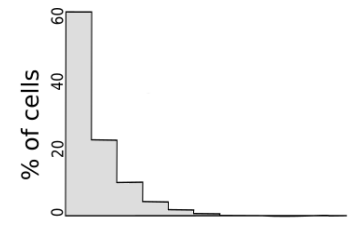

\section{Caco-2}
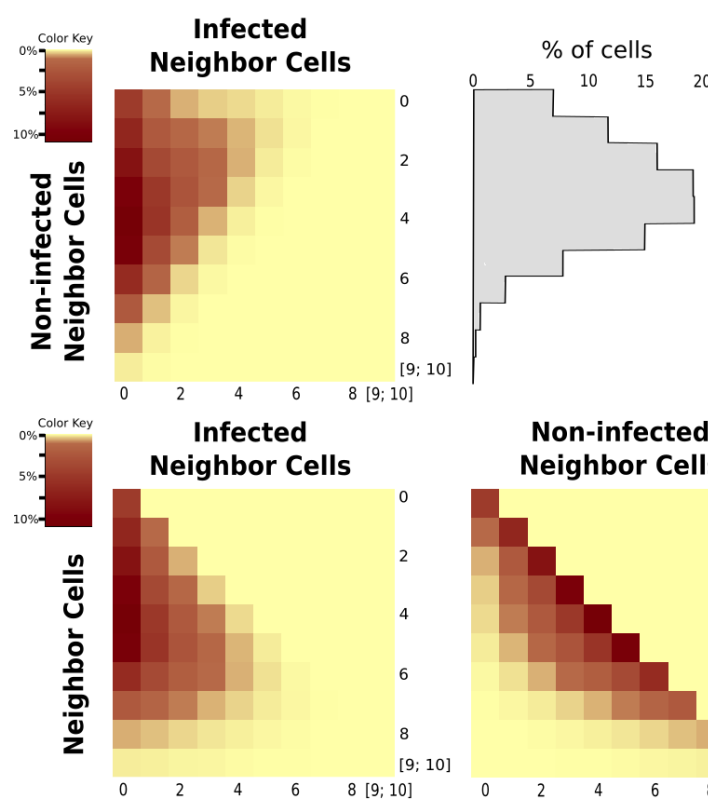

Non-infected
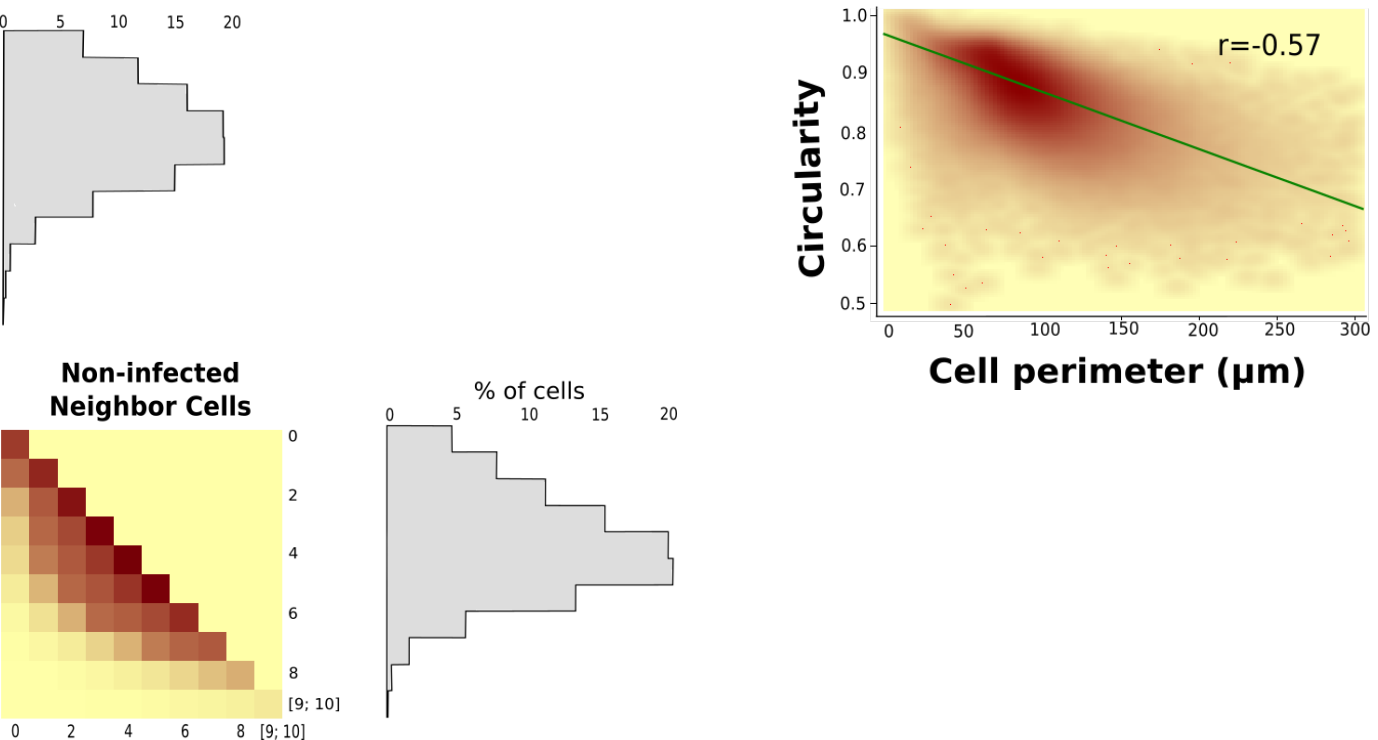

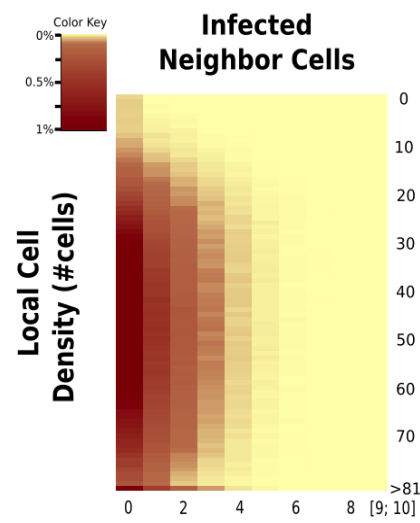

Non-infected Neighbor Cells

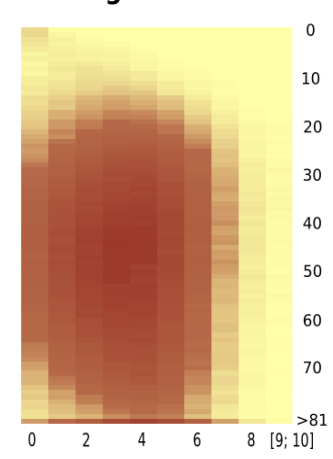

Neighbor Cells

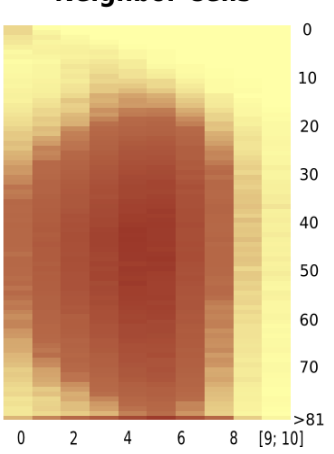

Non-infected Neighbor Cells

Neighbor Cells

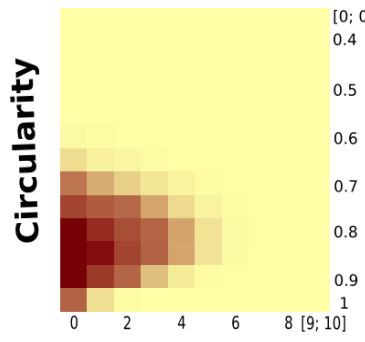

Infected Neighbor Cells

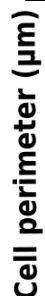

틀

Fig.S7. Scatter plot and heat-map of the different cell parameters studied in Caco-2 cells model allowing to evaluate the relation between these parameters. Grey histograms represent the distribution of the parameter in the entire cell population. 
A.

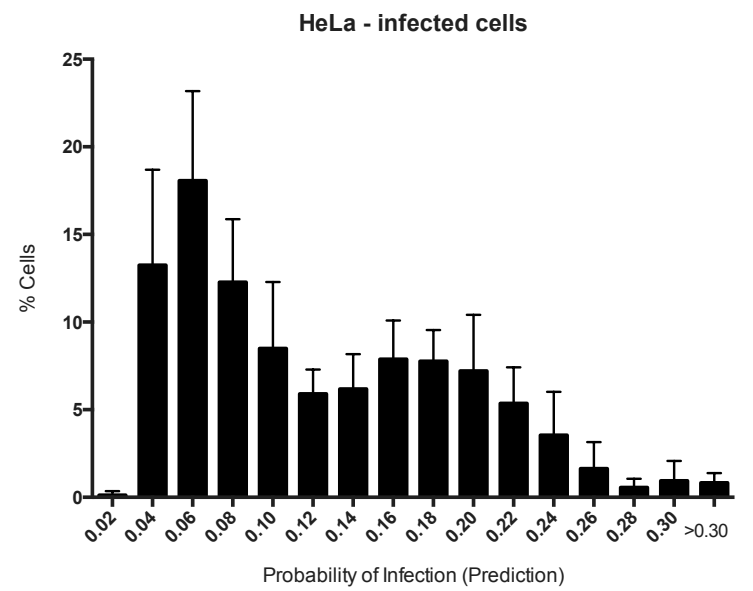

C.

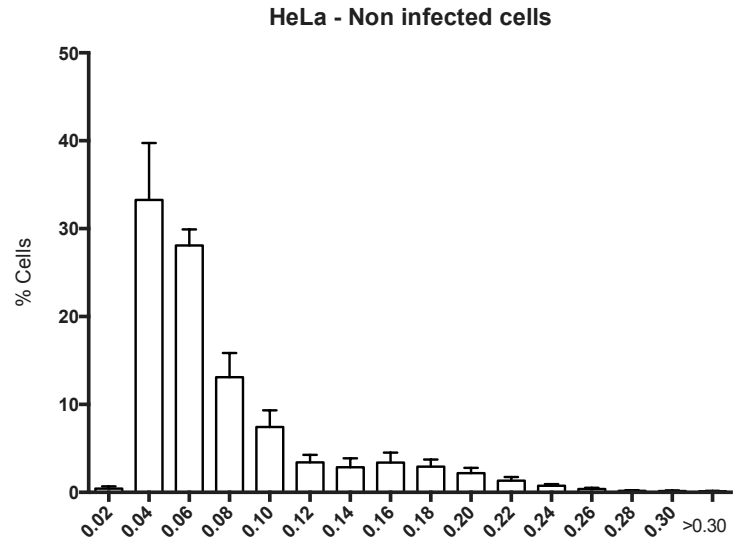

Probability of Infection (Prediction)

E.

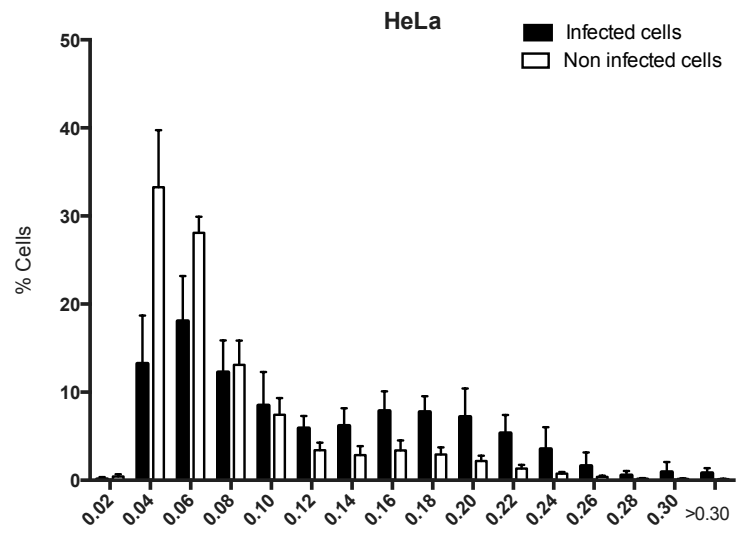

Probability of Infection (Prediction)

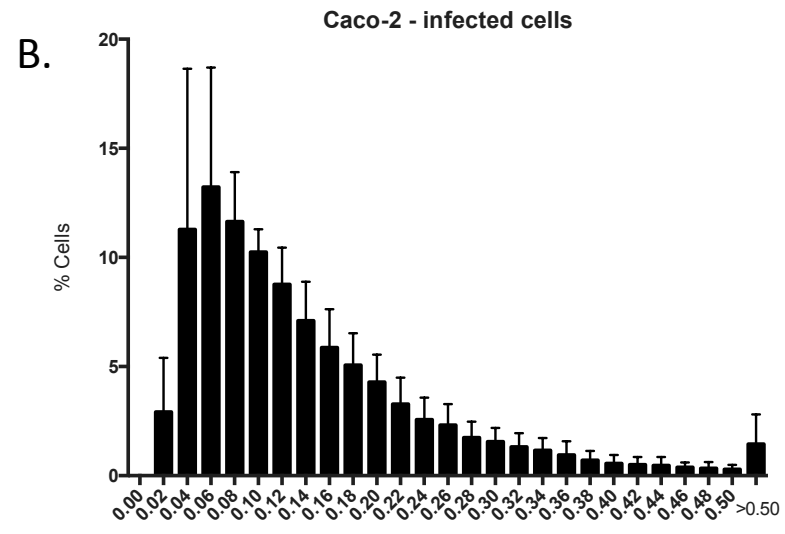

Probability of Infection (Prediction)

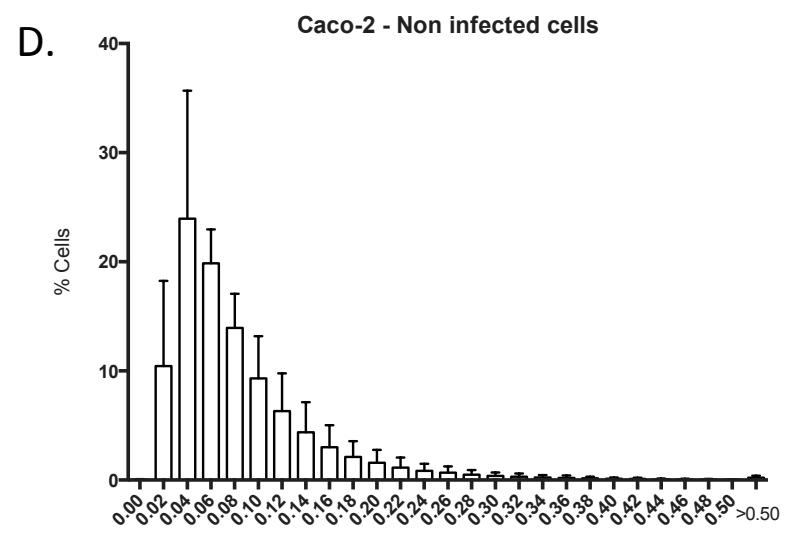

Probability of Infection (Prediction)

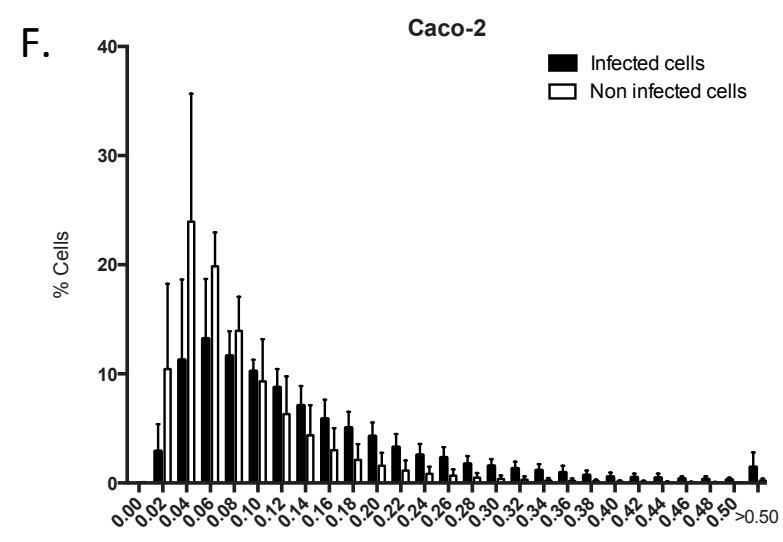

Probability of Infection (Prediction)

Fig.S8. Distribution of the predicted probability of infection at single-cell level for infected and non infected cells. A-C-E. HeLa cells. B-D-F. Caco-2 cells. 
A.

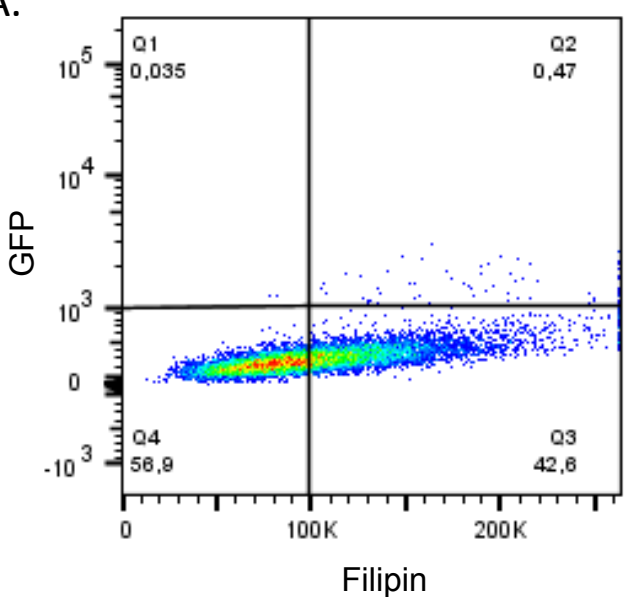

B.

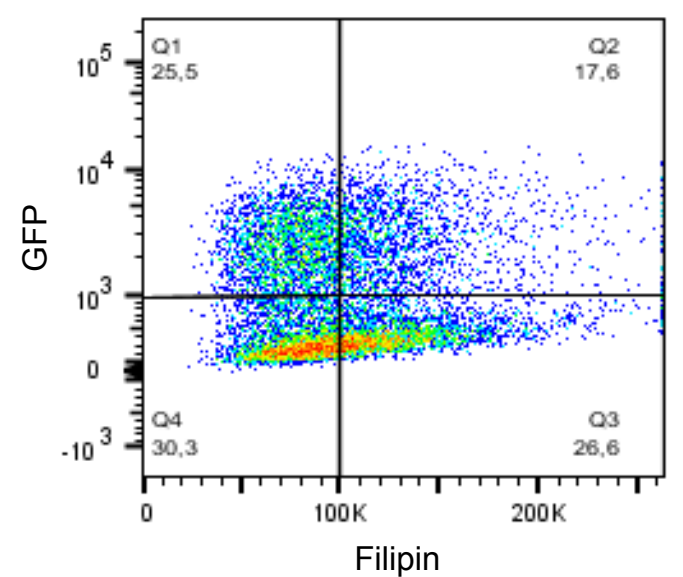

C.

\begin{tabular}{|c|c|c|c|c|c|}
\hline Cholesterol Level & \#Cells & $\%$ Cells total & Infection & \#Cells & $\mathrm{P}$ (inf | Chol.level) \\
\hline 1 & 3937 & 19.9 & \begin{tabular}{|c|} 
Infected \\
Non-infected \\
\end{tabular} & \begin{tabular}{|l|}
1630 \\
2307
\end{tabular} & 0.414 \\
\hline 2 & 3925 & 19.9 & \begin{tabular}{|c|} 
Infected \\
Non-infected \\
\end{tabular} & \begin{tabular}{|l|}
1327 \\
2598
\end{tabular} & 0.338 \\
\hline 3 & 3909 & 19.8 & \begin{tabular}{|c|} 
Infected \\
Non-infected \\
\end{tabular} & \begin{tabular}{|l|}
1129 \\
2780
\end{tabular} & 0.289 \\
\hline 4 & 3921 & 19.9 & \begin{tabular}{|c|} 
Infected \\
Non-infected \\
\end{tabular} & \begin{tabular}{r|}
960 \\
2961
\end{tabular} & 0.245 \\
\hline 5 & 3830 & 19.4 & \begin{tabular}{|c|} 
Infected \\
Non-infected \\
\end{tabular} & $\begin{array}{r}885 \\
2945 \\
\end{array}$ & 0.231 \\
\hline
\end{tabular}

D.

P(inf | Chol. level)

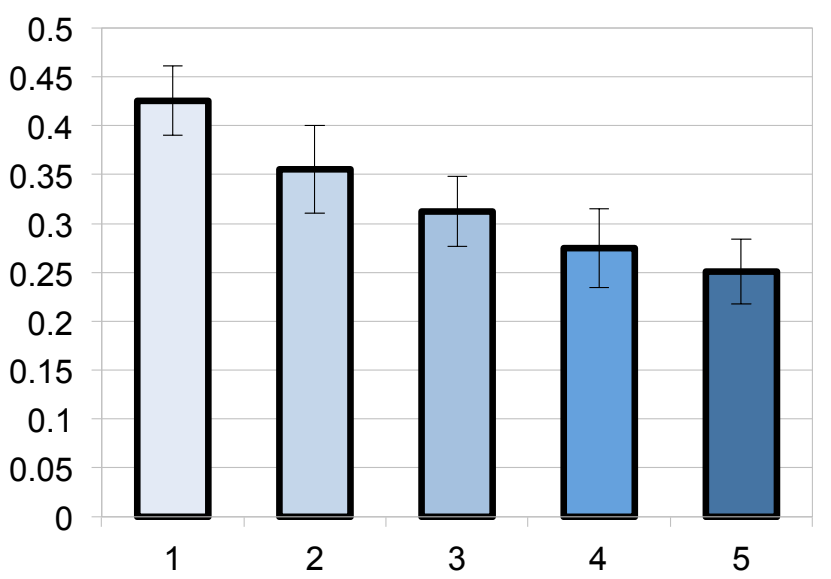

Cholesterol level

Fig.S9. Illustration of FACS acquisition and data processing. A-B. Heat map of Filipin fluorescence as measure of the host cholesterol level (horizontal axe) and GFP fluorescence representing Salmonella-GFP infection (vertical axe). The dials [Q1,Q2] and [Q3,Q4] correspond to the non-infected (A) and the infected cells respectively (B). C. Raw data obtained after binning of the total cell population in 5 categories of cholesterol level (from the lowest to the highest) containing approximately the same number of cell (column 1 to 4). Conditional probability of infection for each category of cholesterol level based on the raw data $\left(5^{\text {th }}\right.$ column). D. Representation of the conditional probability of infection for each category of cholesterol level. 